\title{
1 Dopamine D2Rs Coordinate Cue-Evoked Changes in Striatal Acetylcholine Levels
}

3 Kelly M. Martyniuk ${ }^{1,2}$, Arturo Torres-Herraez ${ }^{2,3}$, Marcelo Rubinstein ${ }^{4}$, Marie A.

4 Labouesse ${ }^{2,5,6}$, Christoph Kellendonk ${ }^{2,3,7}$

61 Department of Neuroscience, Columbia University, 1051 Riverside Drive, New York,

7 NY 10032

82 Department of Psychiatry, Columbia University, 1051 Riverside Drive, New York, NY $9 \quad 10032$

103 Division of Molecular Therapeutics, New York State Psychiatric Institute, 1051 Riverside

11 Drive, New York, NY 10032

124 Instituto de Investigaciones en Ingeniería Genética y Biología Molecular, Consejo

13 Nacional de Investigaciones Científicas y Técnicas, and Departamento de Fisiología,

14 Biología Molecular y Celular, Facultad de Ciencias Exactas y Naturales, Universidad de

15 Buenos Aires, 1428 Buenos Aires, Argentina

165 Department of Health Science and Technology, ETH Zurich, Schorenstrasse 16, 8603

17 Schwerzenbach, Switzerland

186 Zurich Neuroscience Center, Winterthurerstrasse 190, 8057 Zurich, Switzerland

197 Department of Molecular Pharmacology and Therapeutics, Columbia University, 1051

20 Riverside Drive, New York, NY 10032 


\section{Abstract:}

33 In the striatum, acetylcholine (ACh) neuron activity is modulated co-incident with

34 dopamine (DA) release in response to unpredicted rewards and reward predicting cues

35 and both neuromodulators are thought to regulate each other. While this co-regulation

36 has been studied using stimulation studies, the existence of this mutual regulation in vivo

37 during natural behavior is still largely unexplored. One long-standing controversy has

38 been whether striatal DA is responsible for the induction of the cholinergic pause or

39 whether D2R modulate a pause that is induced by other mechanisms. Here, we used

40 genetically encoded sensors in combination with pharmacological and genetic

41 inactivation of D2Rs from cholinergic interneurons (CINs) to simultaneously measure ACh

42 and DA levels after CIN D2R inactivation. We found that CIN D2Rs are not necessary for

43 the induction of cue induced dips in ACh levels but regulate dip lengths and rebound ACh

44 levels. Importantly, D2R inactivation strongly decreased the temporal correlation between

45 DA and Ach signals not only at cue presentation but also during the intertrial interval. This

46 points to a general mechanism by which D2Rs coordinate both signals. At the behavioral

47 level D2R antagonism increased the latency to lever press, which was not observed in

48 CIN-selective D2R knock out mice. This latency correlated with the cue evoked dip length

49 supporting a role of the ACh dip and it's regulation by D2Rs in motivated behavior.

50 Overall, our data indicate that striatal DA coordinate phasic ACh and DA signals via CIN

51 D2Rs which is important for the regulation of motivated behavior.

52

53

54

55 


\section{Introduction:}

Dopamine (DA) plays a key role in learning, serving as a teaching signal that reflects reward prediction error (Day et al., 2007; Mohebi et al., 2019; Nasser et al., 2017; Schultz et al., 1997; Steinberg et al., 2013). This teaching function is encoded in the 67 phasic bursting of DA neurons, which induces a rapid but transient increase of extracellular DA. DA is initially released in response to an unpredicted reward, but with learning the response shifts away from the reward outcome towards reward predicting cues (Schultz, 2007; Schultz et al., 1997).

Like DA neurons, cholinergic interneurons (CINs) in rodents and their presumed counterparts, "tonically active neurons" (TANs), in primates modulate their activity in response to reward predicting cues and salient outcomes. CINs represent about $1-2 \%$ of

74 the neurons in the striatum and regulate mental processes including reinforcement learning, action selection, associative learning, and cognitive flexibility (Aoki et al., 2015; Bradfield et al., 2013; Joshua et al., 2008; Matamales et al., 2016; Maurice et al., 2015; Morris et al., 2004; Okada et al., 2014). Pharmacogenetic inhibition of CINs in the NAc also increases the influence of appetitive cues on instrumental actions pointing to a role of striatal ACh in motivation (Collins et al., 2019). CINs are tonically active and show a

80 multiphasic response to salient and conditioned stimuli that can include a short excitation 81 followed by a prominent pause and rebound excitation (Aosaki et al., 1994a; Aosaki T,

82 1994b; Apicella, 2007; Apicella et al., 2009; Apicella et al., 2011). This multiphasic 83 response in CIN firing coincides with phasic activation of midbrain DA neurons that 84 terminate in the striatum (Joshua et al., 2008; Morris et al., 2004; Schultz, 2007; Schultz 85 et al., 1997). Furthermore, there is increasing evidence that DA and ACh regulate each 86 other within the striatum (Cachope \& Cheer, 2014; Cachope et al., 2012; Chuhma et al., 87 2014; Cragg, 2006; Helseth AR, 2021; Kharkwal et al., 2016; Straub et al., 2014; Sulzer 88 et al., 2016; Threlfell et al., 2012; Yan \& Surmeier, 1991).

89 Here, we will focus on the DA-regulation of the multiphasic ACh response. One 90 long-standing discussion in this regard has been whether the cholinergic pause is 91 dependent on DA via DA D2R receptor (D2R) mediated inhibition of CINs. Early evidence 92 that the CIN pause is DA dependent originate from studies in non-human primates 93 (NHPs). In vivo electrophysiological recordings from TANs have revealed a pronounced 
94 pause in firing to a reward-predicting stimulus. This pause was entirely abolished by 195 methyl-4-phenyl-1,2,3,6-tetrahydropyridine (MPTP) lesions of DA neurons and local 96 administration of a D2R antagonist (Aosaki et al., 1994a; Watanabe \& Kimura, 1998).

97 Consistent with this, more recent slice physiology studies in rodents have shown that 98 pauses in CIN activity can be induced by local application of DA or DA terminal 99 stimulation, which both are eliminated by pharmacological blockade of D2Rs (Augustin et 100 al., 2018; Chuhma et al., 2014; Straub et al., 2014; Wieland et al., 2014). Additionally, 101 optogenetic stimulation of NAc DA terminals results in a pause in CIN firing and this pause 102 is prolonged when D2Rs are selectively overexpressed in CINs (Gallo et al., 2021). Lastly, 103 pauses generated by DA or local stimulation of the striatum are eliminated in a selective 104 CIN D2 knockout mouse (Augustin et al., 2018; Kharkwal et al., 2016). Taken together, 105 the slice physiology experiments provide evidence that the CIN pause can be induced by 106 DA activation in a CIN D2R dependent manner while the NHP studies show the necessity 107 for DA and D2Rs for the generation of the pause.

108 However, more recent evidence suggests that the CIN pause is not induced by DA 109 but by cortical, thalamic, or long-range GABAergic inputs (Brown et al., 2012; Cover et 110 al., 2019; Ding et al., 2010; Doig et al., 2014; English et al., 2012; Matsumoto et al., 2000; 111 Zhang et al., 2018). Consistent with this, stimulation of cortical and thalamic inputs to the 112 striatum in slices or in vivo induces a triphasic cholinergic pause. One model suggests 113 that the cholinergic pause is generated by intrinsic properties of CINs. When CINs come 114 out of the early glutamatergic excitation, voltage-gated potassium channels (Kv7.2/7.3) 115 open and induce an after-hyperpolarization that induces the pause. In this model DA plays 116 a role in augmenting the intrinsically induced pause (Zhang et al., 2018). Consistent with 117 this, thalamo-striatal stimulation induced a pause that was shortened but not fully 118 abolished by a D2R antagonist (Cover et al., 2019). However, in earlier influential slice 119 physiology experiments, the pause induced by thalamic stimulation was fully blocked by 120 D2R antagonism suggesting that activation of DA release from intrastriatal DA terminals 121 was responsible for pause generation (Ding et al., 2010).

122 One limitation of the mechanistic studies in rodents has been that they relied on 123 stimulation experiments rather than on DA evoked by natural stimuli. While the early NHP 124 studies suggested necessity for DA in inducing the pause during behavior, these studies 
125 lacked the cellular specificity for excluding the possibility that the effects of 126 pharmacological D2R blockage were due to inhibiting D2Rs on CINs vs other neuronal 127 populations.

$128 \quad$ Here, we used genetically encoded biosensors (Labouesse \& Patriarchi, 2021) to 129 simultaneously monitor DA and ACh in the dorsal striatum during behavior in mice with 130 pharmacological blockade and/or selective ablation of D2Rs from CINs. Using this 131 approach, we addressed the question whether the natural stimulus induced pause is fully 132 dependent on DA or not. We first determined whether changes in DA and ACh levels 133 occur simultaneously to reward-predicting stimuli in mice as has been shown in NHPs via 134 electrophysiological recordings of DA and TAN neurons (Morris et al., 2004). In vivo 135 imaging of $\mathrm{ACh}$ and DA levels revealed cue-induced decreases in striatal $\mathrm{ACh}$ and 136 increases in DA levels, confirming the ability to measure concomitant ACh dips and DA 137 peaks with functional imaging. Using a Pavlovian learning task, we confirmed that both 138 signals co-occur and develop in parallel during the training of the task. Using a simpler 139 reinforcement task that enables better quantification of the neuromodulator signals, we 140 quantified cue-induced changes in DA and ACh changes after manipulating D2R function.

141 We found that selective ablation of D2Rs from CIN or blocking D2Rs in control mice with 142 the selective D2R antagonist eticlopride did not abolish the stimulus-induced decrease in 143 ACh levels. Rather it shortened the length of dip and enhanced ACh rebound levels in a 144 dose dependent manner. This indicates that DA is necessary for controlling the overall 145 shape of the ACh dip. During simultaneous recordings experiments, the relationship 146 between DA and ACh was strongest in response to reward predicting cues but still present 147 during the intertrial interval supporting a general mechanism by which DA coordinates 148 ACh levels. At the behavioral level, D2R antagonism increased latency to lever press to 149 a reward-paired lever, but this relationship was abolished when we inactivated CIN D2Rs. 150 Moreover, cue evoked changes in ACh levels correlated with the latency to press, 151 altogether supporting a role of the ACh dip in motivated behavior. 
Materials and methods:

Animals

Adult male and female C57BL/6J (JAX stock \# 000664) mice (Figures 1-6 \&10) were bred in house. For control and KO animals (Figures 7-10): double-transgenic mice were generated by crossing heterozygous ChAT-ires-Cre mice (Rossi et al., 2011) (JAX stock \#006410) to homozygous $\operatorname{Drd} 2^{f / f f l}$ (Drd2 $2^{f / f l}$ ) mice (Bello et al., 2011). Control (Drd2 $2^{f / f l}$ ) and

163 ChATDrd2KO (ChAT-ires-Cre $\times$ Drd2 ${ }^{f / f f}$ ) mice are littermates, bred in house and back 164 crossed onto C57BL/6J background. Mice were housed 1-4 per cage for most 165 experiments on a 12-hr light/dark cycle, and all experiments were conducted in the light 166 cycle. All experimental procedures were conducted following $\mathrm{NIH}$ guidelines and were 167 approved by Institutional Animal Care and Use Committees by Columbia University and 168 the New York State Psychiatric Institute.

Pharmacology

171 Intraperitoneal injections of saline, eticlopride (Tocris Cat. No. 1847) $(0.1,0.25,1.0,2.5$ 172 and $5.0 \mathrm{mg} / \mathrm{kg}$ ) or scopolamine (Tocris Cat. No. 1414) $(15 \mathrm{mg} / \mathrm{kg}$ ) were administered $1 \mathrm{hr}$ 173 before behavioral testing. To generate a dose-response curve with eticlopride, saline 174 days alternated with drug days and the drug was administered in order from the lowest to 175 highest dose.

\section{Surgical procedures}

178 Mice ( $\geq 8$ weeks old) were induced with $4 \%$ isoflurane and maintained at $1-2 \%$ throughout 179 the procedure. Mice were bilaterally injected with $450 \mathrm{~nL} /$ hemisphere with either AA5180 hSYN-dLight1.2 (Addgene) (Patriarchi et al., 2018) or AA5-hSYN-ACh3.0 (Vigene) (Jing 181 et al., 2020) (also known as GRAB-ACh3.0) into separate hemispheres of the dorsal 182 medial striatum (DMS) using stereotactic Bregma-based coordinates: AP, $+1.1 \mathrm{~mm}$; ML $183 \pm 1.4 \mathrm{~mm}$; DV, $-3.1 \mathrm{~mm},-3.0 \mathrm{~mm}$ and $-2.9 \mathrm{~mm}$ (150 nL/DV site). For the optogenetic 184 inhibition experiment, mice were co-injected unilaterally with AA5-hSYN-ACh3.0 and 185 AAV5-EF1 $\alpha-D I O-$ eNpHR3.0 (UNC Vector Core) into the DMS. Following virus injection, $186400-\mu \mathrm{m}$ fiber optic cannulas (Doric, Quebec, Canada) were carefully lowered to a depth 
187 of $-3.0 \mathrm{~mm}$ and fixed in place to the skull with dental cement anchored to machine mini188 screws. Groups of mice used for experiments were housed in a counterbalanced fashion 189 that accounted for sex, age, and home cage origin. Cannula-implanted mice began 190 behavioral training 4 weeks after surgery. At the end of experiments, animals were 191 perfused, and brains were processed post-hoc to validate virus expression and optic fiber location as in (Gallo et al., 2021).

In vivo fiber photometry and optogenetics

195 Fiber photometry equipment was set up using two 4-channel LED Driver (Doric) connected to two sets of a 405-nm LED and a 465-nm LED (Doric, cLED_405 and 197 cLED_465). The $405 \mathrm{~nm}$ LEDs were passed through 405-410 nm bandpass filters, while 198 the $465 \mathrm{~nm}$ LEDs were passed through a 460-490 nm GFP excitation filters using two 6port Doric minicubes. 405 and 465 LEDs were then coupled to a dichroic mirror to split excitation and emission lights. Two low-autofluorescence patch cords (400 $\mu \mathrm{m} / 0.48 \mathrm{NA}$, Doric) arising from the 2 minicubes were attached to the cannulas on the mouse's head 202 and used to collect fluorescence emissions. These signals were filtered through 500-540 203 nm GFP emission filters via the same minicubes coupled to photodetectors (Doric, gain 204 set to DC Low). Signals were sinusoidally modulated, using Synapse® software and 205 RZ5P Multi I/O Processors (Tucker-Davis Technologies), at $210 \mathrm{~Hz}$ and $330 \mathrm{~Hz}$ (405 nm 206 and $465 \mathrm{~nm}$, respectively) to allow for low-pass filtering at $3 \mathrm{~Hz}$ via a lock-in amplification 207 detector. 405 and $465 \mathrm{~nm}$ power at the patch cord were set to $30 \mu \mathrm{W}$ or below. For acute 208 optogenetic inhibition via eNpHR3.0, amber light (595 nm LED, Doric) was applied 209 through the same optic fiber using a short and long optogenetic protocol: (i) $500 \mathrm{~ms}$

210 square pulses at $1 \mathrm{~mW}+1 \mathrm{~s}$ ramp down; (ii) $500 \mathrm{~ms}+3 \mathrm{~s}$ ramp down. The $595 \mathrm{~nm}$ light 211 was passed through a 580-680 F2 port (photodetector removed) of the same 6-port 212 minicube (Pisansky et al., 2019). The optogenetic experiment was performed in the home 213 cage.

215 Photometry data processing

216 All photometry and behavioral data utilized custom in-house MATLAB analysis scripts. 217 Photometry signals were analyzed as time-locked events aligned to the lever extension 
218 (CRF) or tone onset (Pavlovian) of each trial. The $405 \mathrm{~nm}$ channel was used to control 219 for potential noise/movement artifacts and the $465 \mathrm{~nm}$ channel was used to detect the 220 conformational modulation of either the GACh3.0 sensor by ACh or the dLight1.2 sensor 221 by DA. Both demodulated signals were extracted as a $15 \mathrm{~s}$ window surrounding the event, 222 which was denoted as time $=0$. Both signals were down sampled by a factor of 10 using 223 a moving window mean. The change in fluorescence, $\Delta F / F(\%)$, was defined as (F-F0)/F0 $224 \times 100$, where $F$ represents the fluorescent signal $(465 \mathrm{~nm})$ at each time point. F0 was 225 calculated by applying a least-squares linear fit to the $405 \mathrm{~nm}$ signal to align with the 465nm signal (Calipari et al., 2016). To normalize signals across animals and sessions, 227 we calculated a local baseline fluorescence value for each trial using the average of the $2285 \mathrm{~s}$ period preceding the event and subtracted that from the signal. The daily average GACh3.0 and dLight1.2 traces were calculated using session average traces from 230 individual mice. ACh dip and DA peak amplitudes were calculated as the maximal change 231 of the signal that was at least 1 or 2 STD below or above the local baseline, respectively. ACh dip duration was calculated using the last and the first zero crossings preceding and

233 following the dip. Total AUC was calculated as the area of all three components of the 234 ACh signal (initial peak, dip and rebound). Negative AUC was calculated as the area for 235 only the negative component. Rebound AUC was calculated as the area of the positive 236 component immediately following the dip. The AUC analysis was restricted to a $5 \mathrm{~s}$ time 237 window following the task event. Individual CRF trial $(\Delta F / F(\%))$ traces were used for 238 correlation analysis for CRF trials. For the ITI correlation, we examined any interaction 239 between dLight1.2 and GACh3.0 regardless of event size during the variable $40 \mathrm{~s}$ of the 240 ITI.

Operant apparatus

243 Four operant chambers (model Env-307w; Med-Associates, St. Albans, VT) equipped 244 with liquid dippers were used. Each chamber was in a light- and sound-attenuating 245 cabinet equipped with an exhaust fan, which provided 72-dB background white noise in 246 the chamber. The dimensions of the experimental chamber interior were $24722 \times 18 \times 13 \mathrm{~cm}$, with flooring consisting of metal rods placed $0.87 \mathrm{~cm}$ apart. A feeder 248 trough was centered on one wall of the chamber. An infrared photocell detector was used 
249 to record head entries into the trough. Raising of the dipper inside the trough delivered a

250 drop of evaporated milk reward. A retractable lever was mounted on the same wall as

251 the feeder trough, $5 \mathrm{~cm}$ away. A house light located on the wall opposite to trough

252 illuminated the chamber throughout all sessions.

254 Dipper training

255 Four weeks after surgery, mice underwent operant training. Mice were weighed daily 256 and food- restricted to $85-90 \%$ of baseline weight; water was available ad libitum. In the 257 first training session, 20 dipper presentations were separated by a variable inter-trial 258 interval (ITI) and ended after 20 rewards were earned or after 30 min had elapsed, 259 whichever occurred first. Criterion consisted of the mouse making head entries during 20 260 dipper presentations in one session. In the second training session, criterion was 261 achieved when mice made head entries during 30 of 30 dipperpresentations.

263 Pavlovian conditioning:

264 Mice were trained for 16 consecutive days in a Pavlovian conditioning paradigm, which 265 consisted of 12 conditioned stimulus-positive (CS+) trials and 12 unconditioned stimulus 266 (CS-) trials occurring in a pseudorandom order. Each trial consisted of an 80-dB auditory 267 cue presentation for $10 \mathrm{~s}$ of an $8 \mathrm{kHz}$ tone or white noise (counterbalanced between 268 mice) and after cue offset a milk reward was delivered only in CS+ trials, whereas no 269 reward was delivered in CS- trials. There was a $100 \mathrm{~s}$ variable intertrial interval, drawn 270 from an exponential distribution of times. Head entries in the food port were recorded 271 throughout the session, and anticipatory head entries during the presentation of the cue 272 were considered the conditioned response. Anticipatory responding was calculated as 273 the difference in nose poking during the CS+ quintile with the maximum response (Q4 274 or 5) and the first quintile.

276 Continuous reinforcement schedule (CRF)

277 For lever press training, lever presses were reinforced on a continuous reinforcement 278 (CRF) schedule. Levers were retracted after each reinforcer and were presented again 279 after a variable ITI (average $40 \mathrm{~s}$ ). The reward consisted of raising the dipper for $5 \mathrm{~s}$. The 
280 session ended when the mouse earned 60 reinforcements, or one hour elapsed, 281 whichever occurred first. Sessions were repeated daily until mice achieved 60 282 reinforcements.

284 Data analysis

285 Sample sizes were determined by performing statistical power analyses based on effect 286 sizes observed in preliminary data or on similar work in the literature. Statistical analyses 287 were performed using GraphPad Prism 9 (GraphPad), MATLAB (MathWorks). Data are 288 generally expressed as mean \pm standard error of the mean (SEM). Paired and unpaired 289 two-tailed Student's t-tests were used to compare 2-group data, as appropriate. Multiple 290 comparisons were evaluated by one- or two-way ANOVA and Bonferroni's post hoc test, 291 when appropriate. In rare cases of values missing in repeated measures samples, the 292 data were analyzed by fitting a mixed effects model, as implemented by Prism 9. 293 Photometry correlation analyses were performed using Pearson's correlation coefficients. 294 A p-value of < 0.05 was considered statistically significant. Behavioral findings were 295 replicated with mice from different litters, ages, or sexes. Investigators were blinded to 296 the genotype of mice during behavioral assays as well as throughout the data analysis. 297 Computer code for data analysis is available on Github (username: kmartyniuk1). Files 298 are titled, "DA-ACh_Dualimaging_CRF" and "DA-ACh_Dualimaging_Pavlovian". 


\section{Results:}

\section{GACh3.0 allows for measuring fast decreases in task evoked ACh levels}

315 First, we validated our experimental approach to simultaneously image changes in ACh

316 and DA levels within the same mouse (Figure 1A) during an instrumental task, continuous

317 reinforcement (CRF) (Figure 1B). We aligned our photometry signals to the lever

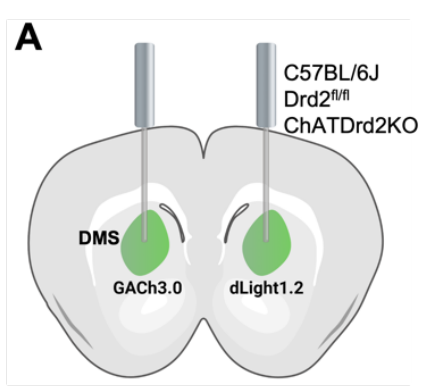

B

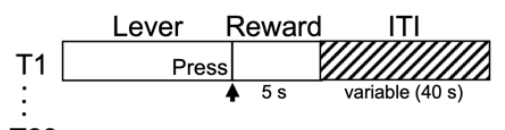

T60

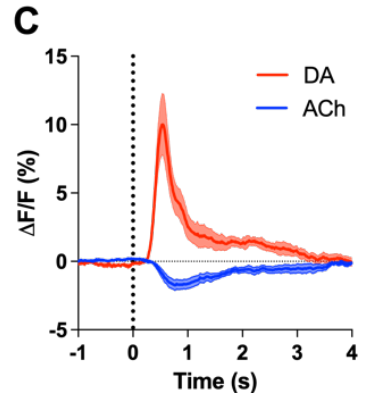

$\mathbf{F}$

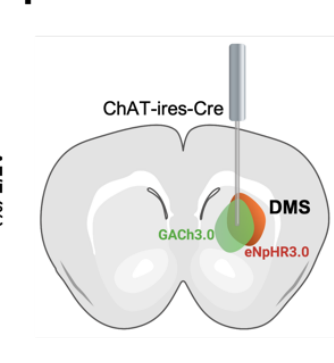

G

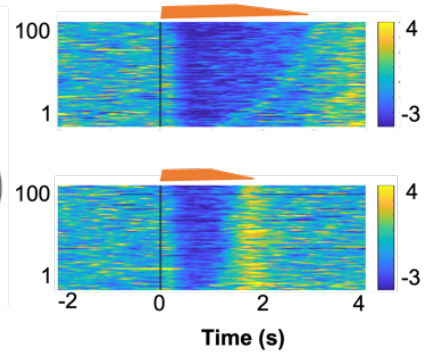

Figure 1. GACh3.0 reliably measures fast decreases in ACh during an instrumental task. (A) Schematic of the surgery setup. All mice were injected with both biosensor viruses (GACh3.0 and dLight1.2) in separate hemispheres of the DMS and counterbalanced across mice. Fiber photometry lenses were bilaterally implanted at the site of viral injection to simultaneously monitor ACh and DA in the same mouse. (B) CRF task design. Mice were trained to press a lever to retrieve a milk reward for 60 trials/day with a variable ITI (40 s). (C) Changes in fluorescence $(\Delta F / F)$ aligned to lever extension (timepoint= $0 \mathrm{~s}$ ). DA levels (red) increased and ACh levels (blue) decreased, $\mathrm{N}=5 \mathrm{mice}$ in trained mice. (D) $15 \mathrm{mg} / \mathrm{kg}$ of scopolamine (green), a mAChR antagonist, blunts the initial ACh peak and dip compared to saline (black) confirming that the GACh3.0 sensor is reporting changes in ACh levels. $N=4$ mice. (E) Heatmap of $A C h$ responses aligned to lever extension (Time $=0 \mathrm{~s}$ ) and sorted by length of ACh decrease for 300 individual trials (60 trials in 5 mice). (F) Schematic of the surgery setup. ChAT-ires-Cre mice were co-injected with GACh3.0 and Credependent halorhodopsin into the DMS and a fiber photometry lens was implanted at the site of viral injection. (G) Approximation of trials with short dips (bottom) and long dips (top) using the short and long optogenetic inhibition protocol (100 trials, 20 trials/ 5 mice).

318 extension, which with training becomes a reward predicting cue. After 3 days of training, 319 we observed an increase in DA (red) and a decrease in ACh (blue) at lever extension 320 presentation (Figure 1C). To confirm that the fluorescent indicator, GACh3.0, is 321 measuring changes in ACh levels (and not movement artefacts or electrical noise), we 
322 measured the GACh3.0 signal in the presence of $15 \mathrm{mg} / \mathrm{kg}$ scopolamine, a M3R 323 muscarinic antagonist, which targets the GACh3.0 parent receptor (M3R). We found that 324 scopolamine, abolished an early increase and the following decrease in ACh levels in 325 response to lever extension when compared to saline injections (Figure 1D).

To confirm that the GACh3.0 sensor has the kinetics to measure a rapid decrease in ACh levels, we expressed the inhibitory opsin eNpHR3.0 in ChAT-ires-Cre mice to 328 selectively inhibit CINs. Lever extension induced decreases in ACh levels within $250 \mathrm{~ms}$ 329 showed varying lengths trial by trial (Figure 1E). Light activation of eNpHR3.0 induced a 330 dip with even shorter latency (latency to dip onset 206.4 [186.8-226.1] ms, n=5 mice), 331 which was followed by a rebound in ACh levels (Figure 1F). The optogenetic experiment 332 was performed in the home cage. This is consistent with CINs displaying rebound activity 333 after injecting hyperpolarizing currents in brain slices (Wilson, 2005) and optogenetic 334 inhibition in vivo (English et al., 2012). Combined, these data show that GACh3.0 can 335 measure fast decreases in ACh levels. It also indicates that ACh release and degradation and/or diffusion are tightly controlled by CIN neuron activity.

Simultaneous development of DA and ACh signals in response to a reward predicting stimulus

To determine whether changes in DA and ACh levels in response to reward 341 predicting stimuli are co-incident, we measured the release of DA and ACh during a classic Pavlovian reward learning task (Figure 2B). Using fiber photometry and genetically

343 encoded fluorescent indicators, we simultaneously imaged DA and ACh in separate 344 hemispheres within the same animal (Figure 2A). On Day 1 of training, we observed an 345 increase in DA (red) and a decrease in ACh (blue) during unexpected reward following 346 the offset of the CS+. Over training, we saw these changes in both DA and ACh shift to 347 the onset of the CS+ tone, while decreasing to the now expected reward. We did not 348 observe these changes during CS- trials. We then related the changes in DA and ACh to 349 changes in anticipatory nose poking during the CS+ as a measure of learning. We found 350 that both DA and ACh signals correlated well with anticipatory head poking in one animal 351 (Figure 2C). However, other mice did not show any anticipatory responding as this task 352 is non-contingent and head poking is not required to obtain the reward during CS+ trials. 
353 These findings indicate that DA and ACh signals co-develop with learning in response to

354 a reward predicting stimulus.

A
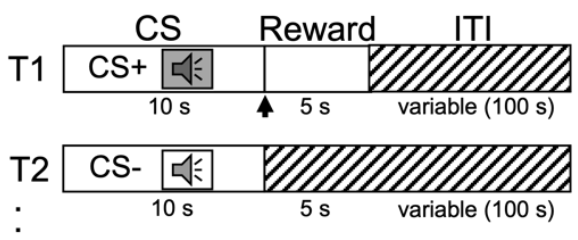

T12
B

CS+

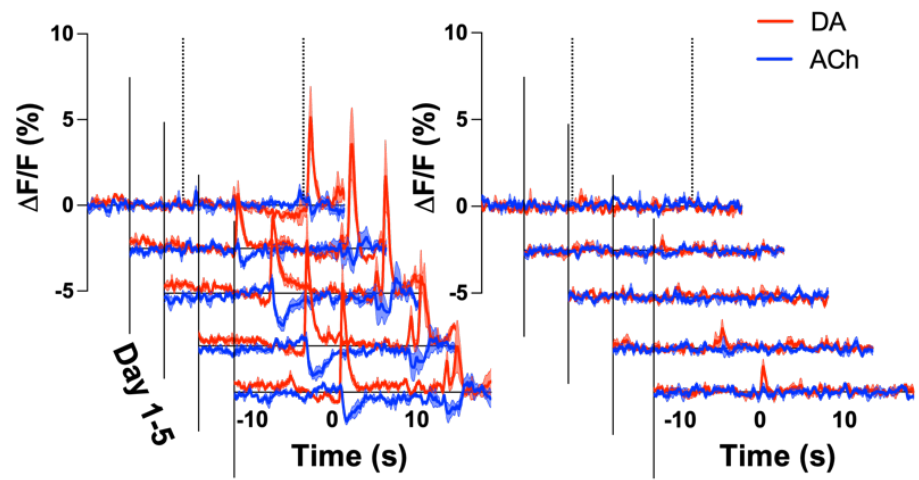

Mouse B

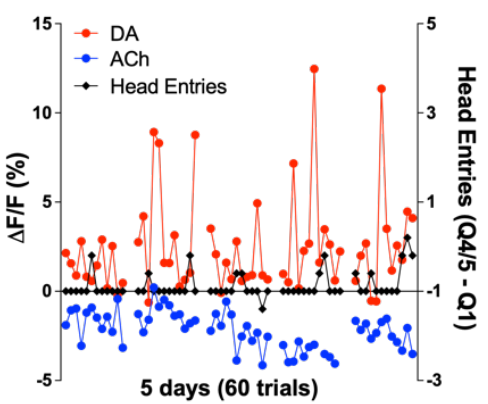

Mouse C

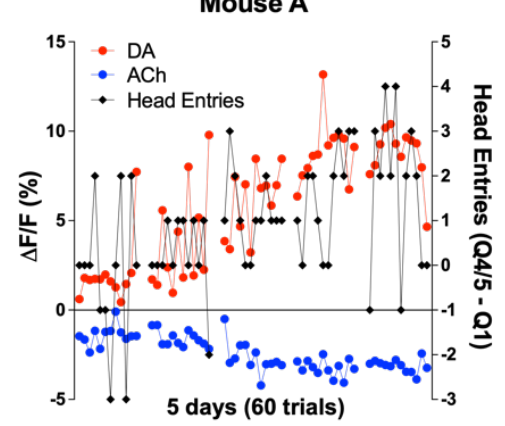

Figure 2. Co-development of DA and ACh signals to a reward predicting cue. (A) Pavlovian task design. Mice were trained on 24 (12 CS+, 12 CS-) trials/day for 5 days. Each trial starts with a 10 s tone (CS+ or CS-). At the end of the CS+ a dipper comes up presenting a milk food reward for $5 \mathrm{~s}$. There is an intertrial interval (ITI) variable in length $(100 \mathrm{~s})$. (B) Changes in fluorescence $(\Delta F / F(\%))$ over 5 days of training for $D A$ (red) and $A C h$ (blue) aligned to CS+ (left) and CS- (right) onset. Signals were averaged over $12 \mathrm{CS}+$ and $12 \mathrm{CS}$ - trials/day, $\mathrm{N}=3 \mathrm{mice}$. (C) Maximum change in DA peak (blue) and ACh dip (red) after CS+ onset over 5 days of training (60 trials) for Mouse A (left). Anticipatory responding (black) is calculated as the difference in nose poking during the CS+ quintile with the maximum responses (Q4 or 5) and the first quintile. Correlations between DA and ACh maxima and behavioral responding: $r=0.4, p<0.002$ and $r=-0.41, p<0.002$, respectively. We did not observe the same correlation between DA/ACh and anticipatory responses in Mouse B (middle) or Mouse C (right).

D2 receptor blockade dose dependently decreases ACh dip lengths and enhances the rebound in ACh levels

359 To determine if the cue induced ACh dip is dependent on DA activation of D2Rs, we used

360 the CRF task as it allows for more trials per session aiding the quantification of the signal.

361 After systemic delivery of the D2R antagonist eticlopride we found a dose-dependent 362 shortening of the ACh dip, which uncovered a rebound following the pause (Figure 3A).

363 We quantified these changes by calculating the area under the curve (AUC), dip length 
364 and dip amplitude. We found that eticlopride significantly reduced the negative AUC 365 (Figure 3B), increased the rebound AUC (Figure 3C), increased the total AUC (Figure

367 by $\mathrm{D} 2 \mathrm{R}$ antagonism (Figures $3 \mathrm{~F}$ ). This suggests that D2Rs do not participate in the initial

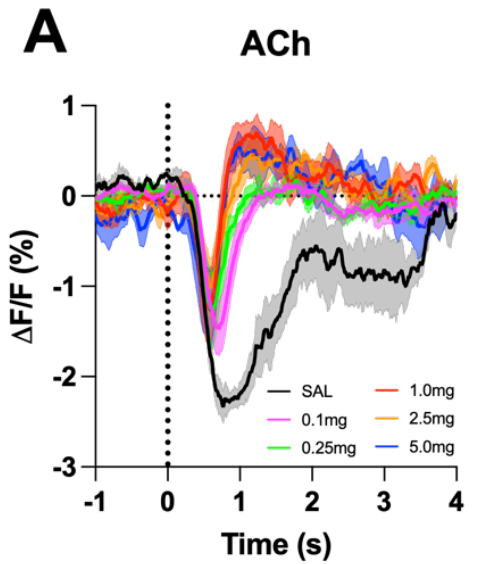

D

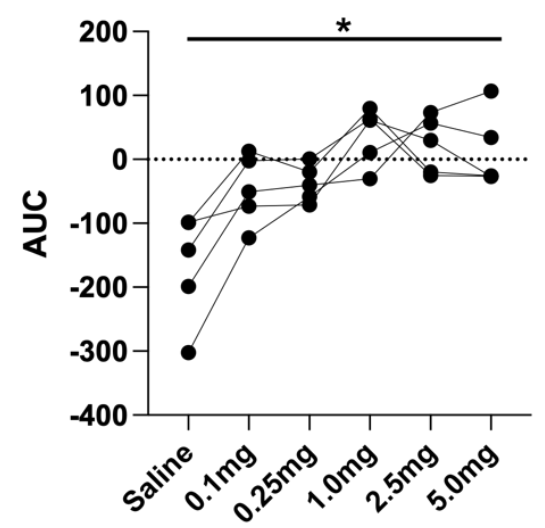

B

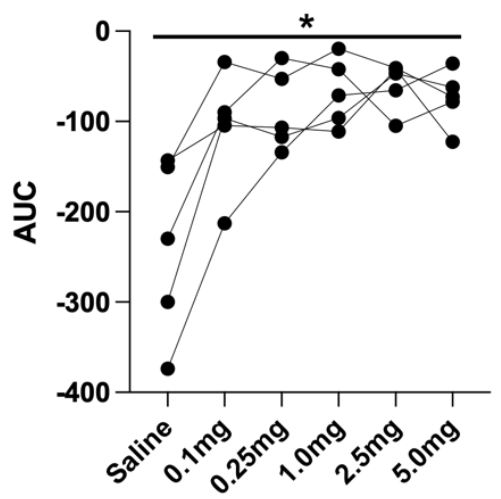

$\mathbf{E}$

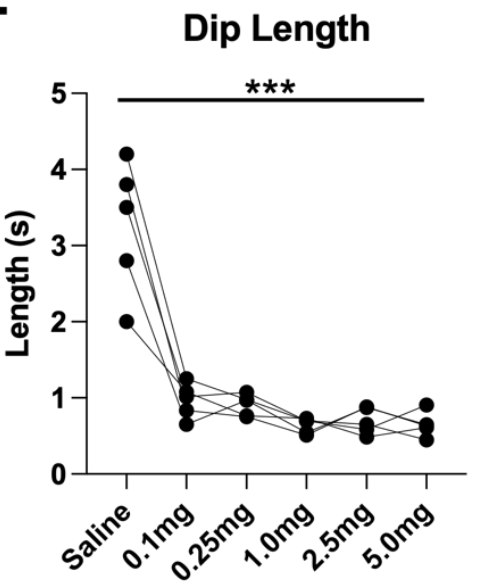

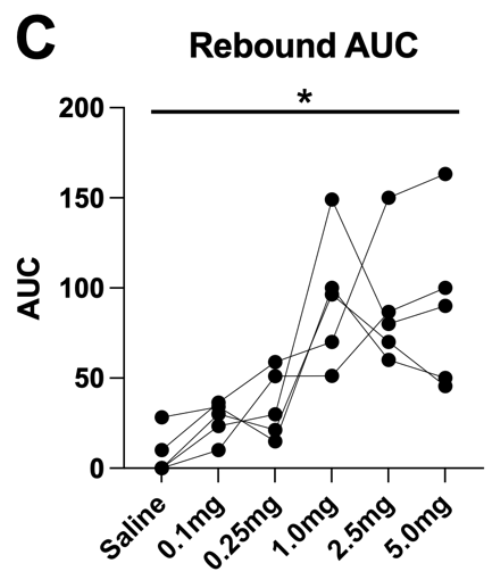

$\mathbf{F}$

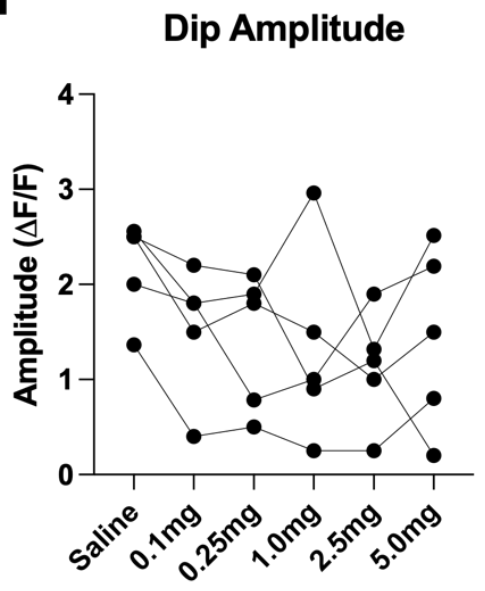

Figure 3. D2R antagonism decreases ACh dip length and enhances rebound. (A) Changes in ACh fluorescence $(\Delta \mathrm{F} / \mathrm{F}(\%))$ aligned to lever extension with saline (black) and increasing doses of eticlopride: $0.1 \mathrm{mg} / \mathrm{kg}$ (pink), 0.25 $\mathrm{mg} / \mathrm{kg}$ (green), $1.0 \mathrm{mg} / \mathrm{kg}$ (red), $2.5 \mathrm{mg} / \mathrm{kg}$ (orange) and $5.0 \mathrm{mg} / \mathrm{kg}$ (blue). (B) Negative AUC is reduced by eticlopride in a dose-dependent manner $\left(F_{(1.694,6.777)}=8.756, p=0.0150\right)$. (C) The rebound AUC is increased by eticlopride in a dose-dependent manner $\left(F_{(1.549,6.197)}=8.833, p=0.0181\right)$ (D) Total AUC is increased by eticlopride in a dosedependent manner $\left(F_{(1.612,6.448)}=8.724, p=0.0170\right)$. $(E)$ Dip length is decreased by eticlopride in a dose-dependent manner $\left(F_{(1.392,5.569)}=36.37, p=0.0009\right)$. $(F)$ The dip amplitude was not affected by eticlopride $\left(F_{(2.063,8.251)}=1.864\right.$, $p=0.2147)$.

369 induction of the ACh dip but do increase the length of the dip and prevent rebound activity

370 following the ACh dip. Since DA neurons are inhibited by D2 auto-receptors, we also

371 analyzed the effect of D2R antagonism on cue induced DA release and quantified

372 changes in peak amplitude and AUC (Figure S1A). We found an overall effect of drug 
373 increasing the peak amplitude (Figure S1B) with the most prominent increase between

374 saline and $0.1 \mathrm{mg} / \mathrm{kg}$. There was no overall effect of drug on the AUC (Figure S1C). These

375 results confirm that blocking D2 auto-receptors on DA neurons increases phasic DA

376 release.

377 Individual CRF trials revealed varying lengths of lever-extension aligned ACh dips

378 that we sorted by lever press latency using a heatmap (Figure $4 \mathrm{~A}$ ). Based on this

A

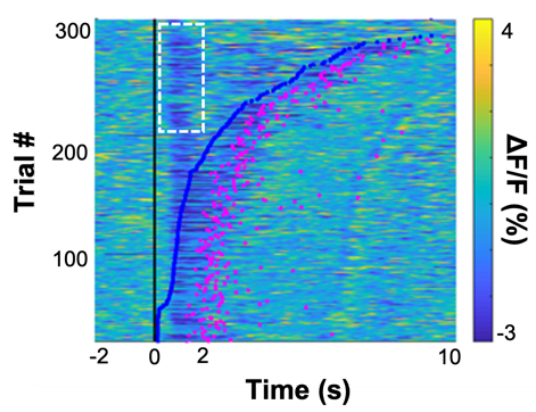

B

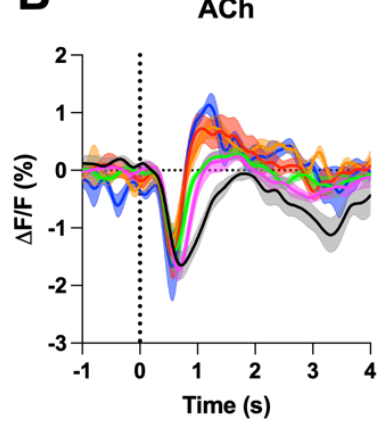

C

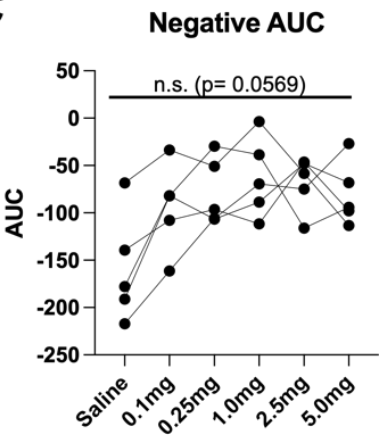

D

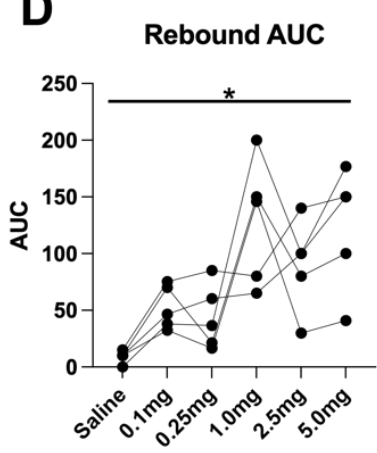

E

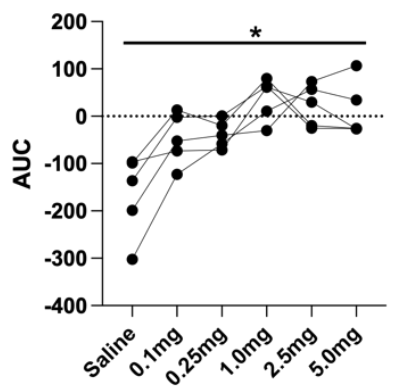

$\mathbf{F}$

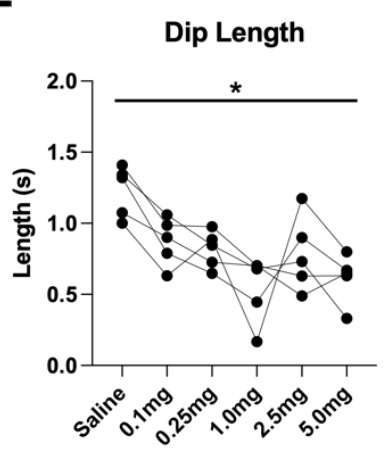

G

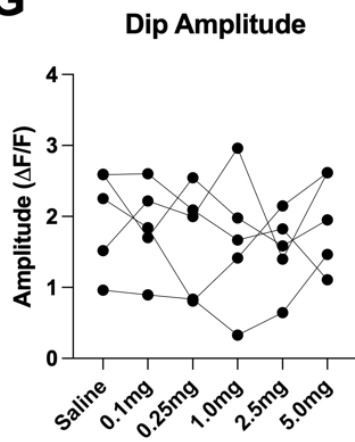

Figure 4. D2R antagonism shortens cue evoked $A C h$ dip and enhances rebound. (A) Heatmap of $A C h$ responses aligned to lever extension (Time $=0 \mathrm{~s}$ ) for 300 individual trials (60 trials in 5 mice) and sorted by response length (bottom). Blue dots show the lever press, and the pink dots show the head entry for each trial. White dashed box represents the cue evoked ACh response to the lever extension where press latencies $>2 \mathrm{~s}$. (B) Changes in ACh fluorescence $(\Delta \mathrm{F} / \mathrm{F}(\%))$ aligned to lever extension for only trials with press latencies $>2 \mathrm{~s}$ with increasing doses of eticlopride. (C) Negative AUC is reduced by eticlopride in a dose-dependent manner $\left(F_{(2.237,8.950)}=3.911, p=\right.$ 0.0569). (D) Rebound AUC is enhanced by eticlopride in a dose-dependent manner $\left(F_{(1.667,6.668)}=8.143, p=0.0184\right)$. (E) Total AUC was increased by eticlopride in a dose-dependent manner $\left(F_{(1.597,6.387)}=8.542, p=0.0182\right)$. (F) Dip length was significantly decreased by eticlopride in a dose-dependent manner $\left(F_{(1.657,6.628)}=6.729, p=0.0284\right)$. $(\mathbf{G})$ Eticlopride had no effect on the dip amplitude $\left(F_{(2.722,10.89)}=0.5379, p=0.6503\right)$.

379 heatmap, we observed longer dips associated with quick press latencies and two smaller dips with slower press latencies with the second dip co-occurring with the lever press.

381 Thus, for press latencies $<2 \mathrm{~s}$ the $\mathrm{ACh}$ is a combination of a cue induced and movement 382 associated pause. To separate the cue induced pause from the movement induced 
383 pause, we analyzed trials with press latencies $>2 \mathrm{~s}$. We still observed a decrease in the 384 ACh dip duration with increasing doses of eticlopride (Figure 4B). Quantification of the 385 negative AUC revealed a non-significant but trending decrease with increasing doses of 386 eticlopride (Figure 4C), while the rebound AUC increased (Figure 4D), the total AUC 387 increased (Figure 4E) and the dip length (Figures 4F) decreased. Eticlopride had no effect 388 on the ACh dip amplitude (Figure 4G). We also examined the effect of D2R antagonism 389 on cue induced DA release for trials with press latencies > 2s (Figure S2A). Quantification 390 of DA peak amplitude (Figure S2B) and AUC (Figure S2C) revealed an overall increase 391 in both measures. Moreover, we found a significant increase between saline and 0.1 $392 \mathrm{mg} / \mathrm{kg}$ eticlopride for DA peak amplitude (Figure S2B). Taken together, these results 393 demonstrate that the cue induced $\mathrm{ACh}$ dip and rebound levels are regulated by 394 cholinergic D2Rs.

D2R blockade decreases negative and enhances positive correlations between DA and $\mathrm{ACh}$

A ACh-DA Trial Correlation

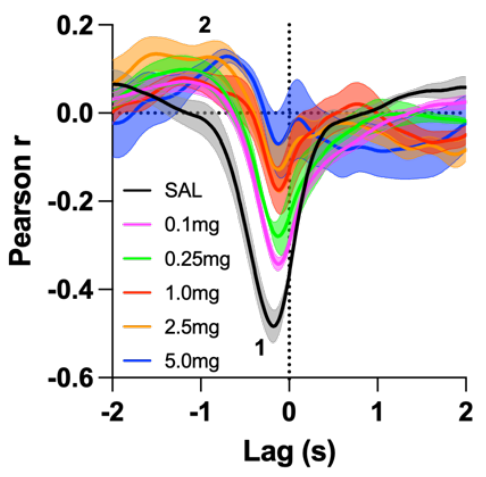

B

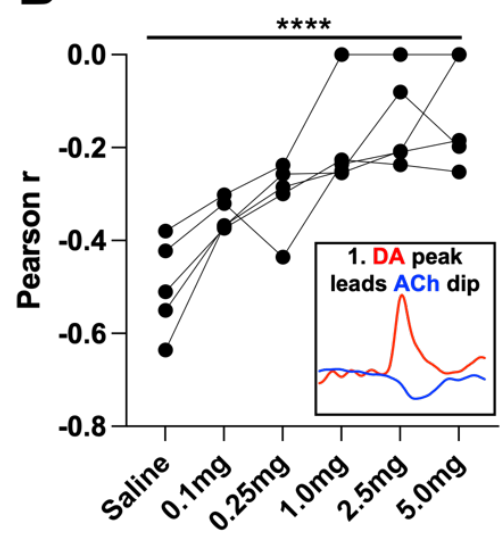

C

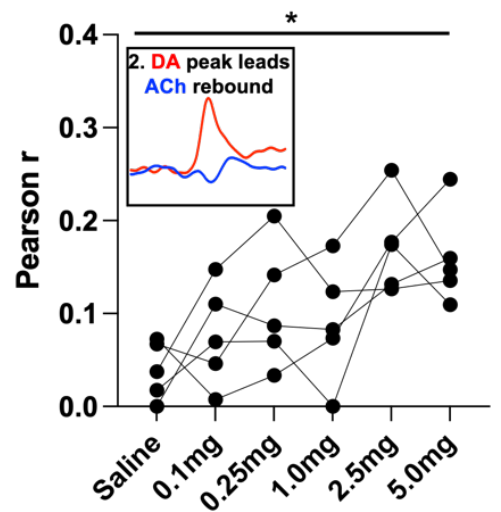

Figure 5. Task dependent ACh-DA interactions are altered by D2R antagonism at lever extension. (A) Correlation between ACh and DA during CRF trials with increasing doses of eticlopride in 5 C57BL/6J mice. The ACh signal moved in front of or behind the DA signal to identify points of highest correlation. The first correlation is a negative correlation (1) with ACh lagging DA ( $\mathrm{Lag}=-178.92 \mathrm{~ms} \pm 14.38 \mathrm{~ms}$ ) and the second correlation is a positive correlation (2) with ACh lagging DA ( $\operatorname{Lag}=-1.5 s \pm 0.138 \mathrm{~s})$. (B) The negative correlation with the DA peak leading the ACh dip (inset) is significantly reduced dose-dependently by eticlopride $(F(3.082,12.33)=18.67, p<0.0001)(C)$ The positive correlation with the DA peak leading the ACh rebound (inset) is enhanced by eticlopride in a dose-dependent manner $\left(F_{(2.325,9.299)}=4.731, p=0.0346\right)$. 
400 ACh recording behind or in front of the DA recording to identify maximal points of 401 correlation. During CRF trials, the strongest correlation is a negative correlation (Figure $4025 A$, label 1, saline: Pearson's $r=-0.475 \pm 0.037, N=5$ ) that occurs when ACh lags DA 403 (Lag= $-178.92 \mathrm{~ms} \pm 14.38 \mathrm{~ms}$ ). This negative correlation, which reflects the ACh dip that 404 follows the DA peak, is reduced with eticlopride in a dose-dependent manner (Figure 5). 405 Next, we found a small positive correlation (Figure 5A, label 2, saline: Pearson's $r=0.039$ $406 \pm 0.014)$ when ACh lags DA (Lag= -1.5 $\mathrm{s} \pm 0.138 \mathrm{~s})$. This positive correlation, which 407 reflects the rebound in ACh, is significantly increased with eticlopride (Figure 5C).
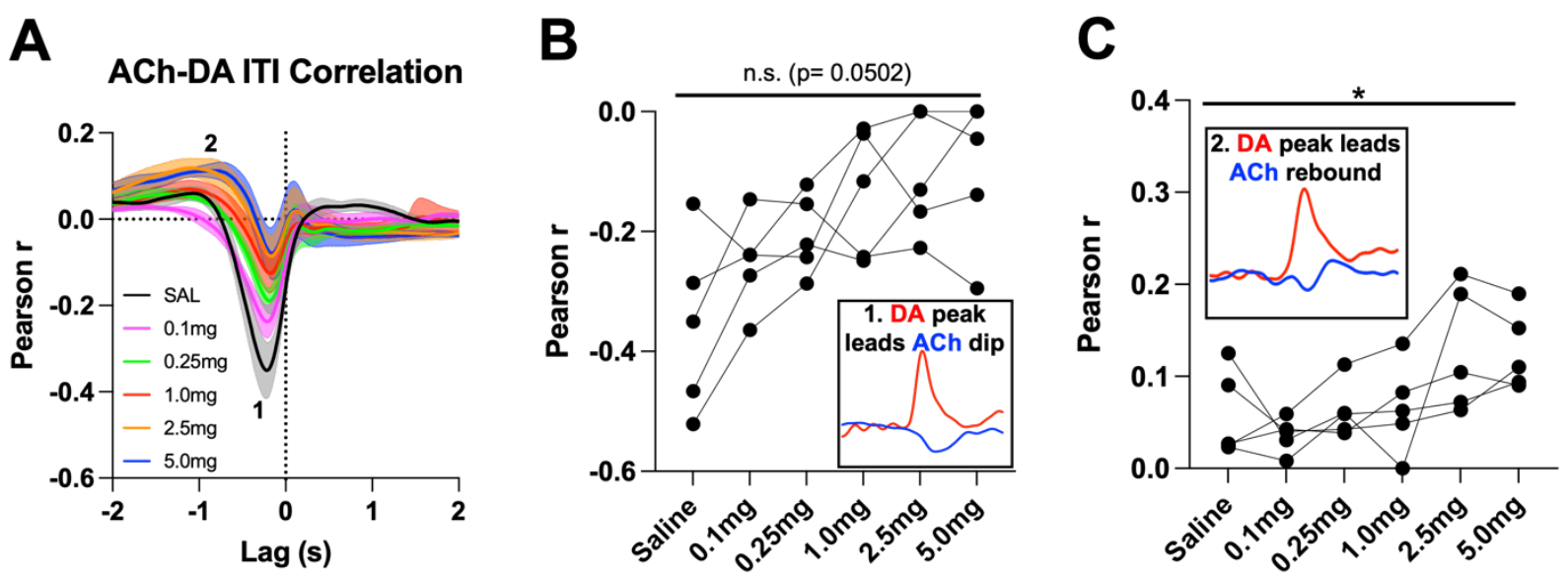

Figure 6. General ACh-DA interactions are altered by D2R antagonism during the ITI. (A) Correlation between ACh and DA during the ITI with increasing doses of eticlopride in C57BL/6J mice. We observe the same two correlations during the ITI: a negative correlation (1) with ACh lagging DA (Lag= $-212.34 \mathrm{~ms} \pm 16.91 \mathrm{~ms}$ ) and a positive correlation (2) with ACh lagging DA ( $\mathrm{Lag}=-1.41 \mathrm{~s} \pm 0.19 \mathrm{~s})$ (B) The negative correlation with the DA peak leading the ACh dip (inset) is decreased by eticlopride in a dose-dependent manner $\left(F_{(1.900,7.598)}=4.606, p=\right.$ 0.0502). (C) The positive correlation with the DA peak leading the ACh rebound (inset) is increased dosedependently by eticlopride $\left(F_{(2.118,8.474)}=4.873, p=0.0377\right)$.

410 a more general mechanism or coordination (Figure 6A). Of note, we looked for any 411 interaction between DA and ACh regardless of event size. Like CRF trials, we observed 412 two correlations during the ITI; DA peak leads ACh dip (Pearson's $r=-0.355 \pm 0.065$ and $413 \mathrm{Lag}=-212.34 \mathrm{~ms} \pm 16.91 \mathrm{~ms}$ ) and DA peak leads ACh peak/rebound (Pearson's $\mathrm{r}=0.058$ $414 \pm 0.021$ and $\mathrm{Lag}=-1.41 \mathrm{~s} \pm 0.19 \mathrm{~s})$. We found that eticlopride decreases the negative 415 correlation in a dose-dependent manner (Figure 6B). Eticlopride also increased the 416 positive correlation, which represents the ACh rebound (Figure 6C). These results 417 indicate that DA-ACh correlations are dependent on D2Rs. While they are strong during 
418 salient cue presentations the relationship between both signals still exists during the 419 intertrial interval reflecting a general mechanism of co-regulation.

\section{Genetic inactivation of D2Rs from CINs decreases dip length}

Systemic eticlopride injections block all D2Rs. To determine the specific

A

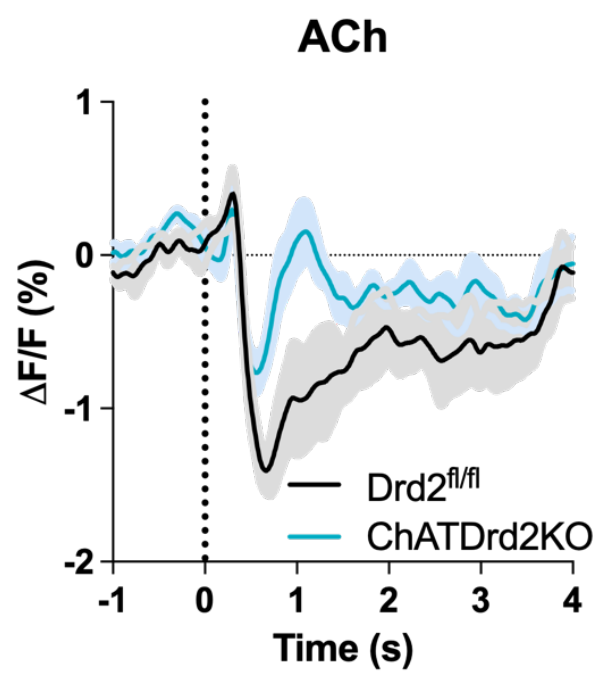

B

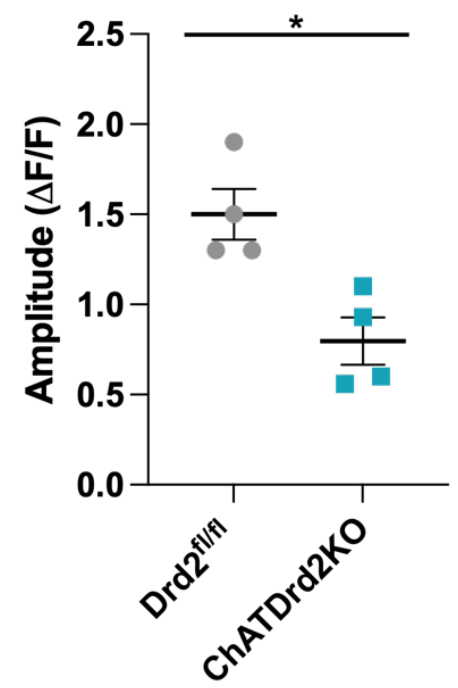

C

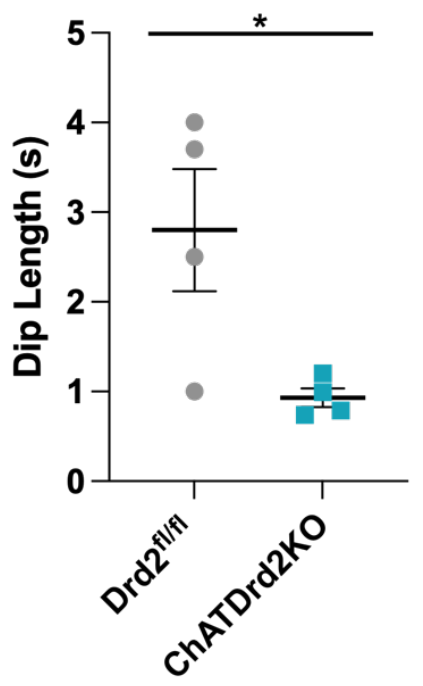

Figure 7. Selective D2R ablation from CINs alters the cue evoked ACh dip. (A) Changes in ACh fluorescence $(\Delta \mathrm{F} / \mathrm{F}(\%))$ aligned to lever extension for only trials with press latencies $>2 \mathrm{~s}$ for Drd2 $2^{\text {fl/fl }}$ control (black) and ChATDrd2KO (blue) mice, $N=4 /$ genotype. (B) Dip amplitude is significantly smaller in ChATDrd2KO animals compared to controls $(p=0.0107)$. (C) Dip length is significantly shorter in ChATDrd2KO mice compared to Drd2/f/fl controls $(p=0.0351)$.

425 smaller and shorter ACh dip in ChATDrd2KO mice (Dip amplitude $=0.797 \Delta \mathrm{F} / \mathrm{F} \pm 0.131$

426 and Dip length $=0.931 \mathrm{~s} \pm 0.105 \mathrm{~s}$ ) compared to control mice (Dip amplitude $=1.50 \Delta \mathrm{F} / \mathrm{F} \pm$

4270.141 and Dip length= $2.80 \mathrm{~s} \pm 0.682 \mathrm{~s}$ ) in trials with press latencies $>2 \mathrm{~s}$ (Figure 7A).

428 Both, the dip amplitude, and dip length were significantly reduced between the two groups

429 (Figure 7B-C). Note that the effects of D2R deletion differed from the highest dose of

430 eticlopride in that ChATDrd2KO mice showed differences in the dip amplitude while 431 eticlopride did not.

432 In contrast to ACh levels, stimulus induced DA release was not altered in 433 ChATDrd2KO mice (Figure S3). This result indicates that loss of cholinergic D2Rs does 
434 not affect stimulus induced DA release and confirm that the effects of DA regulation of 435 the ACh dip are mediated by CIN D2Rs and not an indirect effect by potential changes in 436 DA levels.

438 DA-mediated changes in ACh levels are dependent on CIN D2Rs

439 Next, we determined if D2Rs present in CINs are necessary for the effect of D2R 440 antagonism on modulating the ACh dip. Control Drd2 $2^{\text {fl/f }}$ mice were more sensitive to 441 eticlopride than the C57BL/6J wild-type mice of Figure 4 as they did not complete any 442 trials with the two highest doses, $2.5 \mathrm{mg} / \mathrm{kg}$, and $5.0 \mathrm{mg} / \mathrm{kg}$ (Figure 8A-F). Quantification 443 of the ACh dip using the 3 lower doses revealed a decrease in the negative AUC (Figure $4448 \mathrm{~B}$ ), an increase in the rebound AUC (Figure $8 \mathrm{C}$ ), an increase in the total AUC (Figure 445 8D) and a decrease in dip length (Figure 8E) that were comparable to what we measured 446 in the C57BL/6J mice (Figure 4). Like the C57BL/6J mice, there was no effect on ACh dip 447 amplitude with eticlopride (Figure 8F). In contrast, in ChATDrd2KO mice, we observed no 448 change in the ACh dip with eticlopride (Figure $8 \mathrm{G}$ ) and there was no effect of eticlopride 449 on the negative AUC (Figure 8H), the rebound AUC (Figure 8I), total AUC (Figure 8J), 450 dip length (Figure 8K), or dip amplitude (Figures $8 \mathrm{~L}$ ). These results confirm that D2Rs 451 present in CINs are key players in the modulation of the ACh signal elicited by D2R 452 antagonism. 


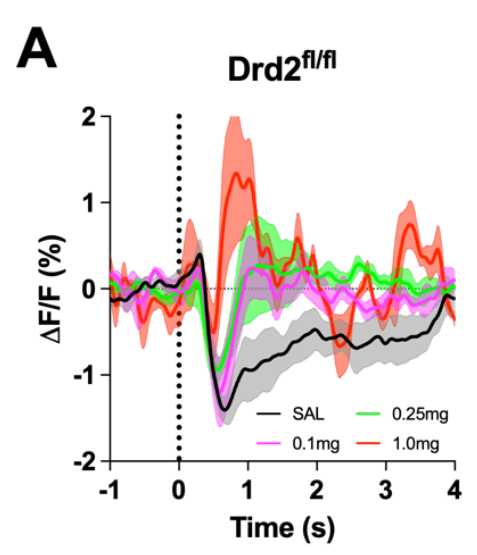

D

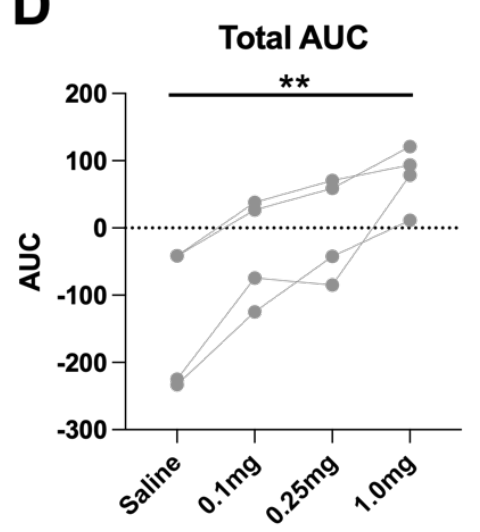

G

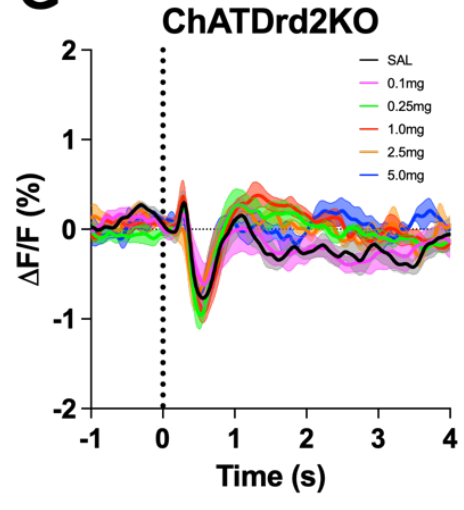

J

Total AUC

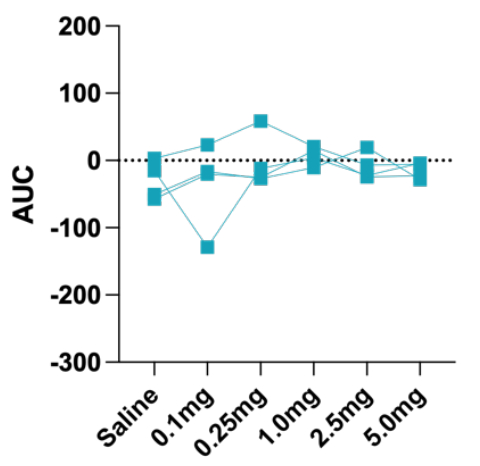

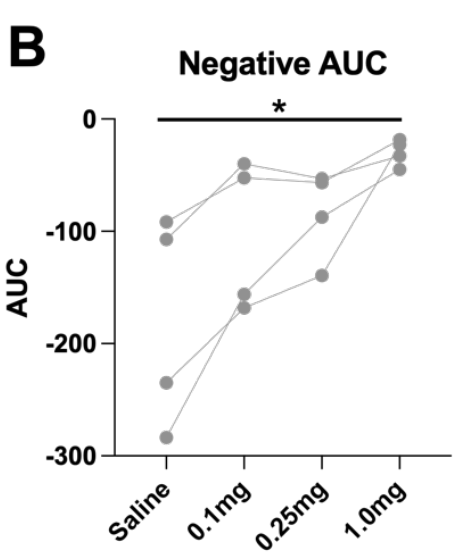

E

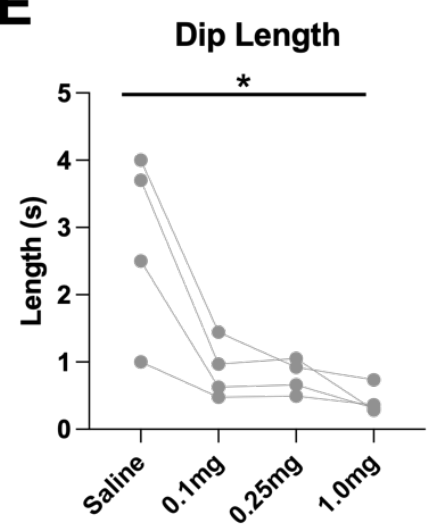

H

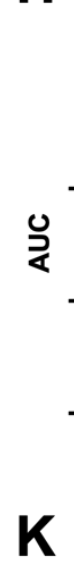

Negative AUC

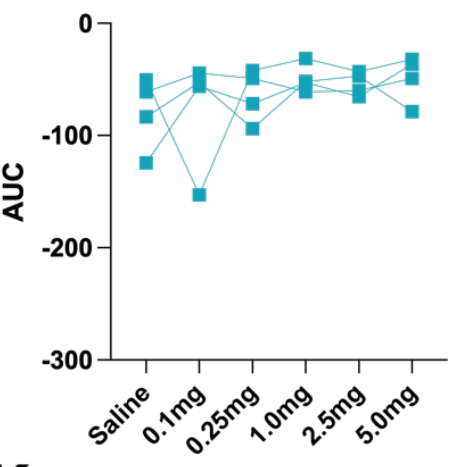

Dip Length

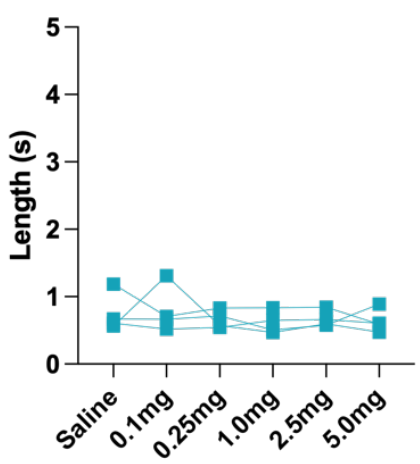

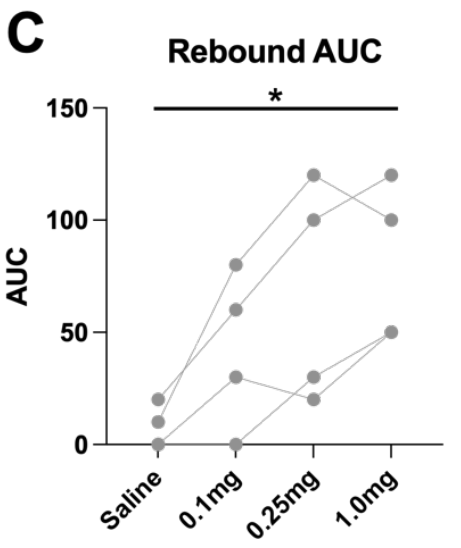

F

Dip Amplitude

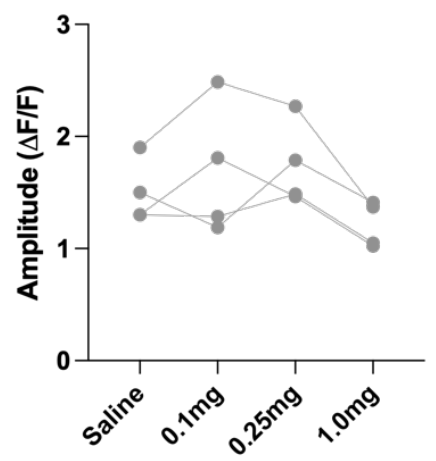

Rebound AUC

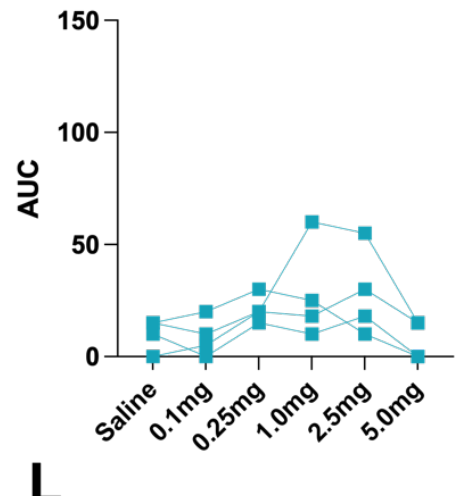

Dip Amplitude

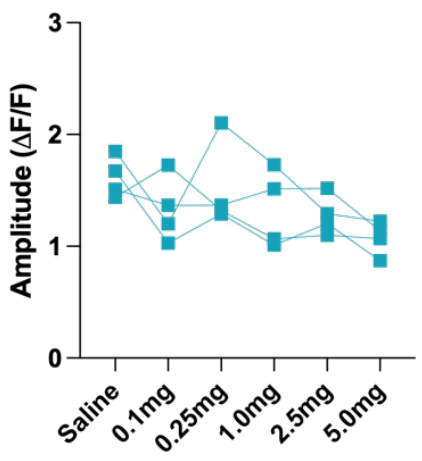


Figure 8. D2R antagonism does not alter the cue evoked ACh dip in ChATDrd2KO mice. (A) Changes in ACh fluorescence $(\Delta \mathrm{F} / \mathrm{F}(\%))$ aligned to lever extension for only trials with press latencies $>2 \mathrm{~s}$ for Drd2/flfl $\mathrm{control}$ mice with increasing doses of eticlopride. (B) Negative AUC is decreased by eticlopride in a dose-dependent manner $\left(F_{(1.387,4.160)}=8.541, p=0.0381\right)$. (C) Rebound AUC is increased by eticlopride in a dose-dependent manner $\left(F_{(1.642,}\right.$ 4.925) $=10.21, p=0.0195)$. (D) Total $A U C$ is increased dose-dependently by eticlopride $\left(F_{(1.525,4.676)}=23.14, p=\right.$ $0.0047)$. (E) Dip length is decreased by eticlopride in a dose-dependent manner $\left(F_{(1.664,4.992)}=9.279, p=0.0226\right)$. (F) Dip amplitude is not affected by eticlopride $\left(F_{(1.433,4.300)}=6.056, p=0.0606\right)$. $(\mathbf{G})$ Changes in ACh fluorescence $(\Delta \mathrm{F} / \mathrm{F}(\%))$ aligned to lever extension for only trials with press latencies $>2 \mathrm{~s}$ for ChATDrd2KO mice with increasing doses of eticlopride. (H) Negative AUC is not affected by eticlopride $\left(F_{(1.663,4.990)}=0.7919, p=0.4803\right)$. (I) Rebound AUC is not affected by eticlopride $\left(F_{(1.706,5.119)}=2.857, p=0.1484\right)$. (J) Total AUC is not affected by eticlopride $\left(F_{(1.844}\right.$, 5.532) $=1.079, p=0.3958)$. $(K)$ Dip length is not affected by eticlopride $\left(F_{(1.848,5.545)}=0.4380, p=0.6516\right)$. (L) Dip amplitude is not affected by eticlopride $\left(\mathrm{F}_{(2.073,6.219)}=2.546, \mathrm{p}=0.1551\right)$.

DA-mediated changes in DA-ACh correlations are dependent on CIN D2Rs

Next, we assessed the effect of CIN D2Rs in the ACh-DA coregulation, again using

Pearson's $r$ correlation analysis and lag analysis. We found that the interaction between DA and ACh was greatly reduced (> 2-fold) in ChATDrd2KO mice compared to Drd2 ff/fl controls (Figure 9). The negative correlation with ACh lagging DA was significantly smaller in ChATDrd2KO mice during both CRF trials (Figure 9A-B) and the ITI (Figure 9C-D) compared to Drd2 f//fl controls. We further examined the role of CIN D2Rs in the synchronization of DA and ACh activity using eticlopride to transiently block CIN D2Rs.

$464 \mathrm{Drd}^{\mathrm{f} / \mathrm{fl}}$ control mice showed a strong negative correlation during CRF trials (Figure 9A: 465 Pearson's $r=-0.521 \pm 0.038, N=4$ ) with $A C h$ lagging $D A(L a g=-167.12 m s \pm 18.82 m s)$ that was reduced by eticlopride (Figure S4B). In addition, a rebound in ACh activity was revealed, which is measured as a positive correlation (Figure S4A: Pearson's $r=0.050 \pm$ $0.030, \mathrm{~N}=4$ ) with $\mathrm{ACh}$ lagging DA ( $\mathrm{Lag}=-1.51 \mathrm{~s} \pm 0.138 \mathrm{~s}$ ) that was increased with increasing doses of eticlopride (Figure $\mathrm{S} 4 \mathrm{C}$ ). During the ITI, the negative correlation between ACh and DA with ACh lagging DA (Figure S5A: Lag= -213.81 ms $\pm 34.14 \mathrm{~ms}$ ) was attenuated by eticlopride (Figure S5B), while the positive correlation with ACh lagging DA (Lag $=-1.39 \mathrm{~s} \pm 0.208 \mathrm{~s}$ ) was not significantly affected by eticlopride (Figure S5C). In

473 ChATDrd2KO mice, neither the negative correlation between ACh and DA (Figure 9A:

474 Pearson's $r=-0.231 \pm 0.046, N=4)$ with $A C h$ lagging after DA (Lag $=-179.41 \mathrm{~ms} \pm 30.66$ $475 \mathrm{~ms}, \mathrm{~N}=4$ ) nor the positive correlation with ACh lagging DA (Lag=-1.635 $\mathrm{s} \pm 0.174 \mathrm{~s}$ ) were 476 affected by eticlopride (Figure S6C). During the ITI, we observed a smaller negative 477 correlation between ACh and DA (Figure 9C: Pearson's $r=-0.153 \pm 0.034, N=4$ ) with ACh 478 lagging DA ( $\mathrm{Lag}=-282.62 \mathrm{~ms} \pm 93.81 \mathrm{~ms}$ ) that was significantly smaller in ChATDrd2KO 
479 mice compared to control 480 mice (Figure 9D) and was not 481 affected by eticlopride 482 (Figure S7A-B). These 483 results it is that D2Rs in CINs 484 that regulate $\mathrm{ACh}$ dip and 485 rebound levels.

D2R antagonism increases the latency to press in a 489 CIN D2R dependent 490 manner

491 We then determined if 492 manipulating CIN D2R 493 function affects behavior in 494 the CRF task.

495 Since D2R blockade induces

496 catalepsy (Kharkwal et al., 497 2016) we wondered whether 498 Drd2 ablation or D2R 499 antagonism alters behavioral 500 responding (latency to press 501 in the task), an indicator of 502 motivated behavior. In

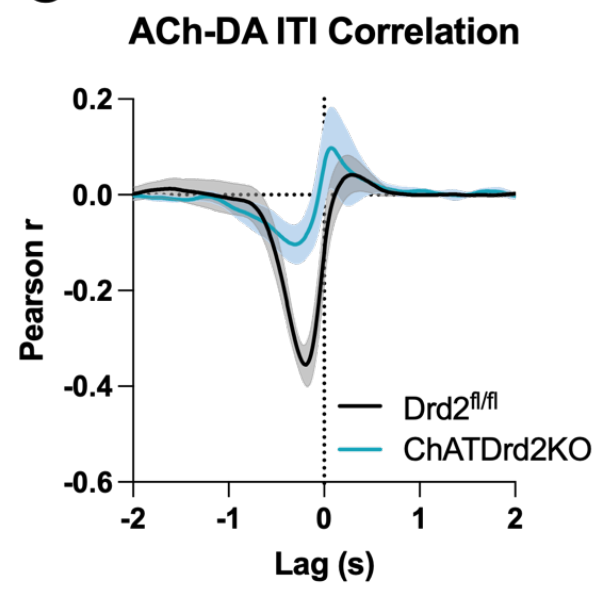

B
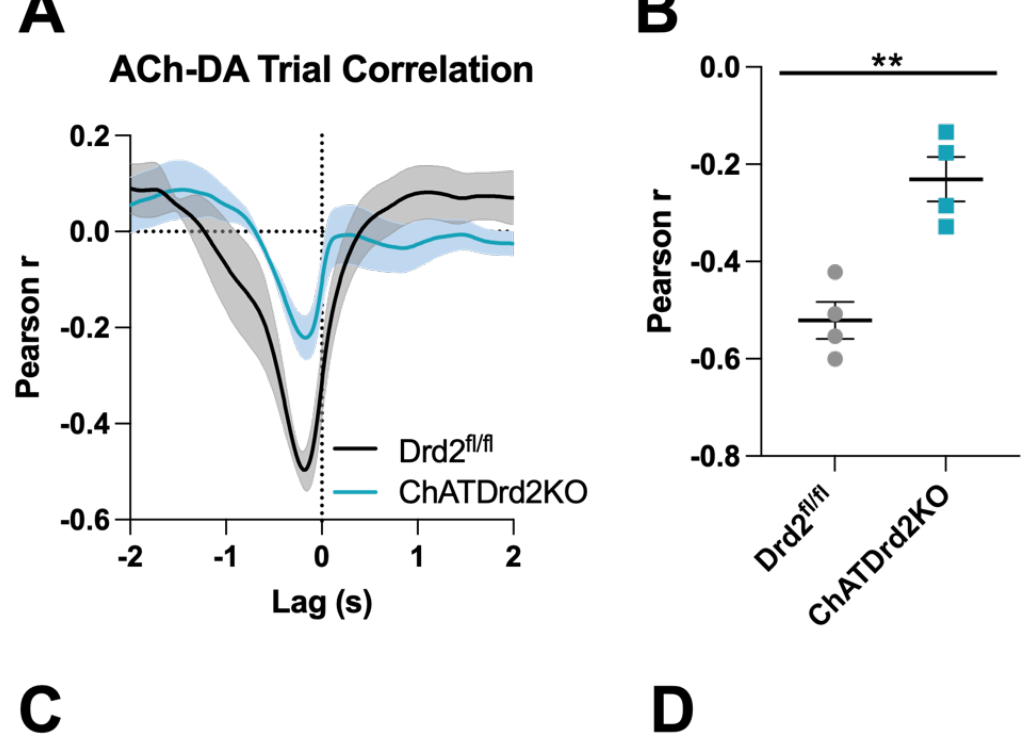

Figure 9. ACh-DA interactions are reduced in ChATDrd2KO mice. (A) Task evoked correlation between ACh and DA for Drd2 $2^{f / f / f}$ control (black) and ChATDrd2KO (blue) mice. (B) The negative correlation with ACh lagging DA is significantly reduced in ChATDrd2KO mice compared to Drd2 $2^{\mathrm{flfl}}$ controls $(p=0.0155)$. (C) Correlation between ACh and DA during the ITI for Drd2 $2^{\mathrm{fl} / f \mathrm{fl}}$ control (black) and ChATDrd2KO (blue) mice. (D) The negative correlation of ACh lagging DA is significantly reduced in ChATDrd2KO mice compared to Drd2 ${ }^{\text {fl/fi }}$ controls $(p=0.0052)$.

503 C57BL/6J mice, we found

504 that eticlopride significantly increased lever press latency in a dose-dependent manner

505 (Figures 10A). Eticlopride had no effect on lever press latency in ChATDrd2KO mice, 506 compared to Drd2 $2^{\text {fl/fl }}$ control mice (Figure 10B). Next, we determined if the size of the 507 stimulus induced ACh dip correlates with behavioral responding. To do this, we analyzed 508 the correlation between the AUC and lever press latency for trials with press latencies > $5092 \mathrm{~s}$ to isolate the stimulus induced ACh dip from the lever press associated dip. In 
510 C57BL/6J mice of Figures 3-6, we found a positive correlation between total AUC and 511 press latency (Figure 10C). Similarly, in Drd2 $2^{f / f l}$ control mice, we found a similar positive 512 correlation between total $\mathrm{AUC}$ and press latency (Figure 10E). This correlation was 513 mainly driven by the ACh dip as the negative AUC positively correlated with press latency 514 for C57BL/6J (Figure 10D) and Drd2 $2^{\mathrm{fl} / \mathrm{fl}}$ control (Figure 10F) mice. This positive correlation 515 between total AUC and press latency was disrupted in ChATDrd2KO animals (Figure 516 10G), while there remained a weaker positive correlation between the negative AUC and 517 press latency (Figure $10 \mathrm{H}$ ). These data suggest that D2R mediated regulation of 518 cholinergic ACh levels contribute to the regulation of motivated behavior. 

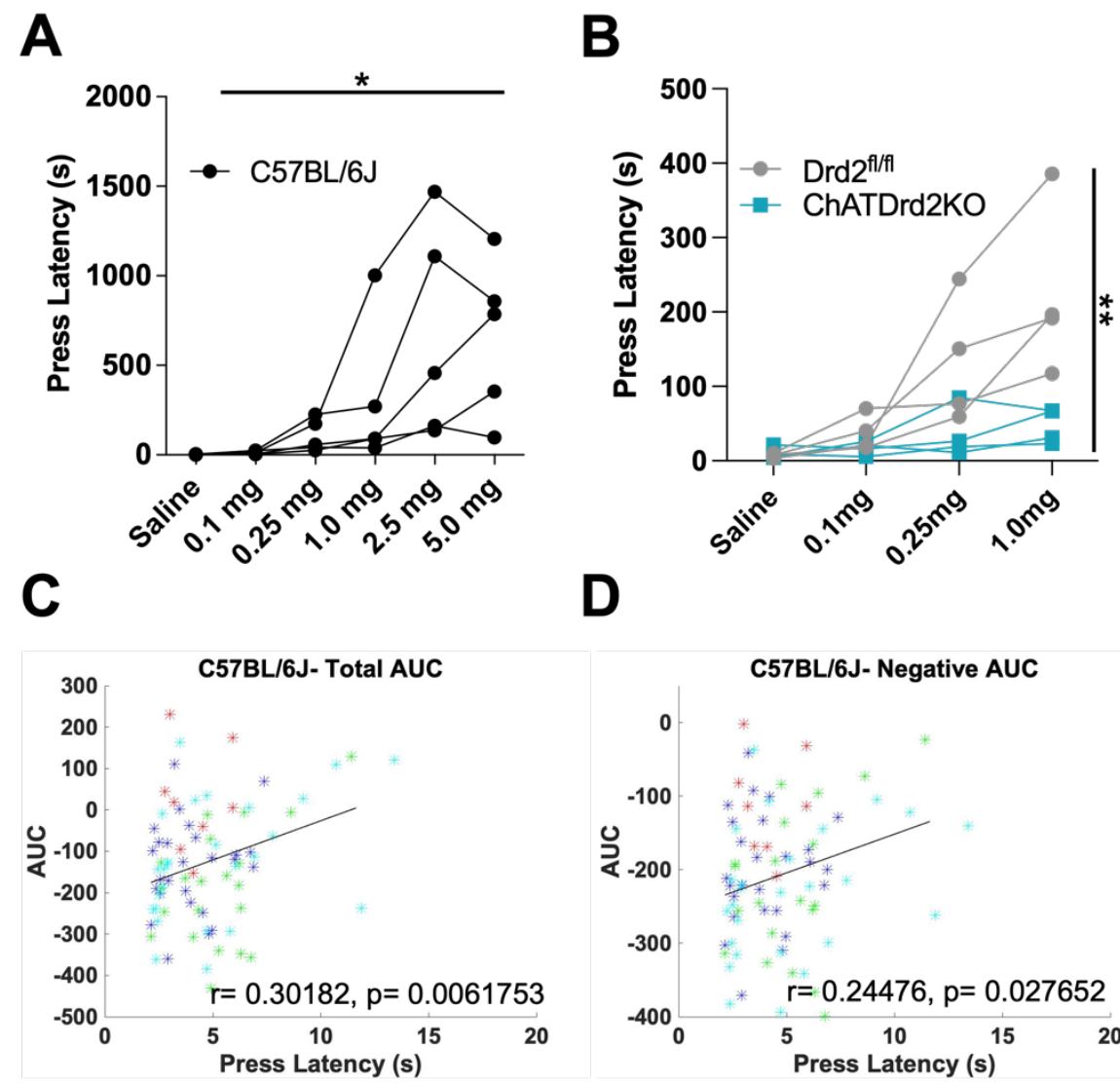

D

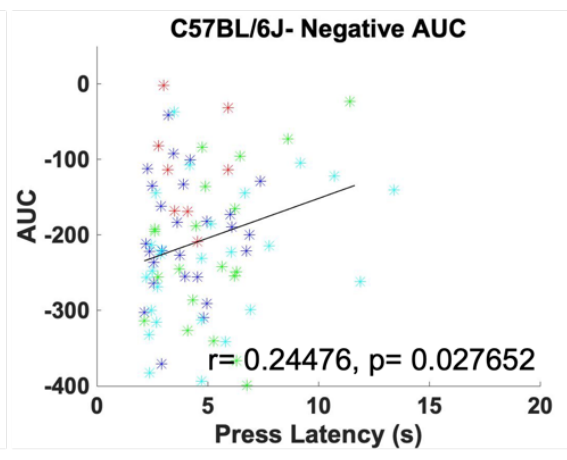

E

F
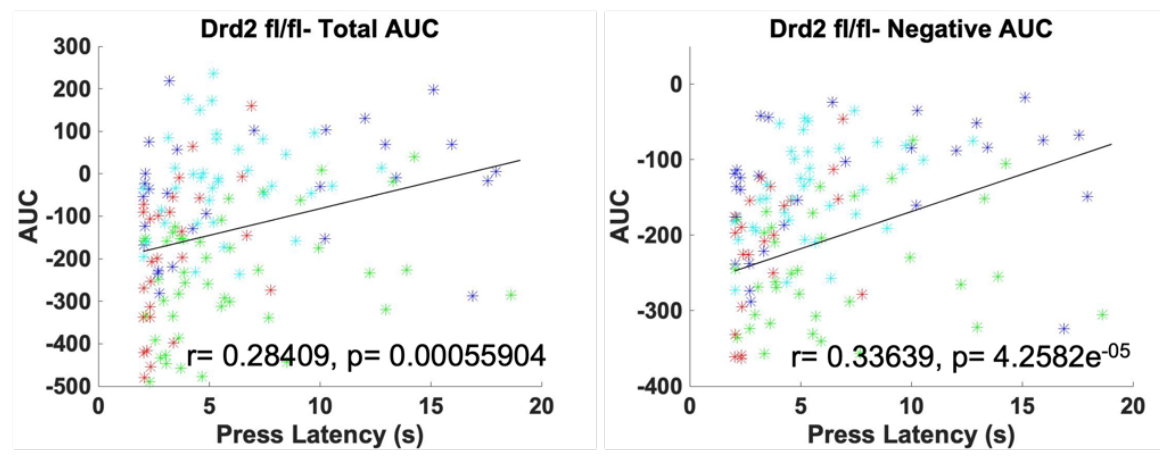

G

H
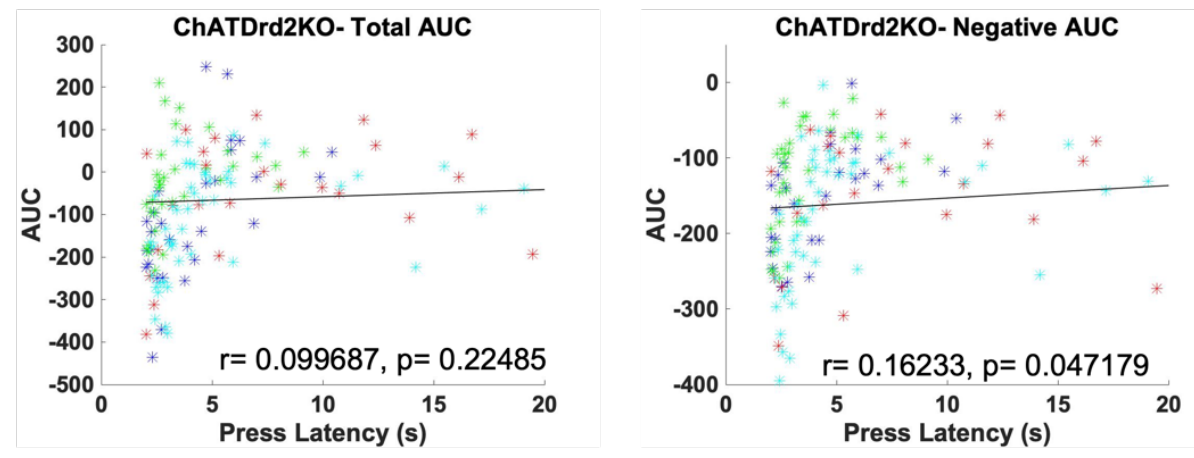
bioRxiv preprint doi: https://doi.org/10.1101/2021.12.08.471871; this version posted December 11,2021 . The copyright holder for this preprint (which was not certified by peer review) is the author/funder, who has granted bioRxiv a license to display the preprint in perpetuity. It is made available under aCC-BY 4.0 International license.

Figure 10. Behavioral responding correlates with $\mathrm{ACh}$ event size but is affected by $\mathrm{D} 2 \mathrm{R}$ antagonism and ablation. (A) Lever press latency is increased by eticlopride in a dose-dependent manner in C57BL/6J mice $\left(F_{(1.383,5.533)}=6.369, p=0.0427\right)$. (B) $\mathrm{D} 2 \mathrm{R}$ antagonism does not increase lever press latency in ChATDrd2KO mice (blue squares) compared to Drd2 ${ }^{f / f l}$ controls (gray circles) $\left(F_{(3,18)}=5.664, p=0.0065\right.$, eticlopride $\mathrm{x}$ genotype). (C) Total AUC positively correlates with lever press latency in C57BL/6J mice ( $r=0.30182, p=0.0061753$ ). (D) Negative AUC positively correlates with lever press latency in C57BL/6J mice $(r=0.24476, p=0.027652)$. (E) Total AUC positively correlates with lever press latency in Drd2 ${ }^{f / / f l}$ control mice $(r=0.28409, p=$ 0.00055904). (F) Negative AUC positively correlates with lever press latency in Drd2 $2^{\mathrm{fl} / \mathrm{fl}}$ control mice $\left(r=0.33639, p=4.2582 e^{-05}\right)$. (G) Total AUC does not correlate with lever press latency in ChATDrd2KO mice $(r=0.099687, p=0.22485)$. (H) Negative AUC positively correlates with lever press latency in ChATDrd2KO mice $(r=0.16233, p=$ $0.047179)$. 


\section{Discussion:}

553 Here, we investigated the mechanism by which striatal DA regulates cue induced

554 changes in ACh levels during behavior. Understanding this mechanism is important

555 because both neuromodulators coincidentally signal salient cues or outcomes during 556 learning and motivated behavior and thus DA may regulate behavior via regulating ACh 557 levels (Apicella et al., 1992). Moreover, it addresses the longstanding question of whether 558 the ACh dip is fully dependent on striatal DA.

559 By simultaneously recording task-evoked DA and ACh levels in mice we made 560 several observations: First, we observed that changes in striatal DA and ACh levels are 561 induced by reward-predicting stimuli and the time locked signals develop in parallel with 562 learning. Second, we found that pharmacological and genetic inactivation of D2Rs does 563 not completely abolish the stimulus-induced dip in ACh, but it does shorten the dip and 564 enhances rebound levels. Third, using correlational analysis, we found a relationship 565 between DA and ACh that was strongest in response to lever extension as a reward 566 predicting cue but still present during the inter-trial interval. This relationship was 567 disrupted by D2R inactivation. Fourth, we found that D2R antagonism increased latency 568 to lever press during behavior, but this was abolished when we inactivated CIN D2Rs. 569 Lastly, the size of the cue evoked ACh dip but not rebound correlated with lever press 570 latency, even for lever presses that happen long after the cued signal has ended. 571 Altogether, these findings indicate that DA and cholinergic D2Rs are necessary for 572 controlling the shape of the ACh dip and the coordinated activity between DA and ACh 573 during reward driven behaviors. Moreover, the cue induced ACh dip correlates and 574 therefore may drive behavioral responding during motivated behavior.

Cue induced changes in striatal DA and ACh levels are time locked and develop in parallel with learning

The changes in DA and ACh levels that we recorded in the Pavlovian conditioning task are consistent with DA neurons and CINs encoding unexpected rewards and reward580 predicting cues (Aosaki T, 1994b; Joshua et al., 2008; Morris et al., 2004; Schultz et al., 581 1997; Watanabe \& Kimura, 1998). Like these previous studies, that assayed neuronal 582 activity, we see a robust increase in DA levels and a decrease in ACh levels to 
583 unexpected reward that diminish as the reward becomes expected. These data show that 584 the neurotransmitter levels of both, DA and ACh, follow neuronal activity of their 585 respective neurons with a sub-second kinetic. The fast induction of the ACh dip is 586 particularly striking as it suggests fast degradation or diffusion of ACh.

587 In addition, we observed similar changes in DA and ACh levels to the conditioned 588 stimulus and not the unconditioned stimulus, which occur in parallel over learning. Our 589 data confirm thus that both DA neurons and CINs respond to salient and conditioned 590 stimuli. Moreover, we found that these changes in DA and ACh levels correlate with 591 behavioral responding. However, this correlation was not observed in all tested mice due 592 to the nature of the Pavlovian task. In the Pavlovian task, animals have the possibility to 593 learn an association between the CS+ and reward. Consequently, some animals may 594 show anticipatory responding during the CS+ (head poking the reward port). However, 595 because anticipatory behavior is not fully required to obtain a reward, some of the tested 596 mice did not exhibit anticipatory head poking. Strikingly, the development of a DA and

597 ACh signal over time indicate that these animals are nevertheless learning the stimulus598 reward association. In conclusion, these data show that task-evoked changes in ACh and 599 DA levels in mice follow what has been described at the level of neuronal activity level in 600 primates (Joshua et al., 2008; Morris et al., 2004; Schultz et al., 1997)

602 D2R inactivation in CINs shortens but does not abolish the cue induced ACh dip

604 in rodents and primates, however, the dependence on DA and CIN D2Rs for pause 605 induction is widely debated (Aosaki et al., 1994a; Morris et al., 2004; Watanabe \& Kimura, 606 1998; Zhang \& Cragg, 2017). Thus, to determine the role D2Rs play in modulating the 607 stimulus induced ACh dip, we pharmacologically blocked D2Rs or selectively ablated 608 Drd2 from CINs and measured ACh and DA levels in the CRF task. We found that D2R 609 blockade or ablation shortened the ACh dip, which we quantified by calculating the dip 610 length. Moreover, in our control mice, D2R blockade also decreased the negative and 611 increased total and rebound AUCs in a dose-dependent manner while the dip amplitude 612 was unaffected. In contrast, D2R blockade had no effect on the stimulus induced ACh dip 613 in ChATDrd2KO mice. This data reveals that the generation of ACh dip is not dependent 
614 on CIN D2Rs. Instead, cholinergic D2Rs are important for modulating the length of the 615 stimulus induced ACh dip. Our data provide clarity on the controversial role that DA plays 616 in the regulation of the ACh dip and suggest that the stimulus induced ACh dip in vivo is 617 not entirely DA or D2R-dependent as studies in primates and slice physiology studies 618 have suggested (Aosaki et al., 1994a; Ding et al., 2010; Watanabe \& Kimura, 1998). Our 619 data further indicates that slice physiology studies in rodents where optogenetic 620 stimulation of DA terminals or caged DA induced CIN pauses are abolished by D2R 621 antagonists or CIN-selective ChATDrd2KO mice are not fully capturing the natural pause 622 (Augustin et al., 2018; Chuhma et al., 2014; Kharkwal et al., 2016; Straub et al., 2014; 623 Wieland et al., 2014).

624 In addition to the effects on dip lengths, we found that CIN D2Rs also regulate the 625 level of ACh rebound levels, acting as a mechanism to constrain ACh rebounds after the 626 dip. Currently, it is unknown which role the rebound in ACh plays during behavior. 627 Generally, CINs are thought to inhibit spiny projections neurons (SPNs) via nicotinic 628 activation of local interneurons or via muscarinic $\mathrm{M}_{2} / \mathrm{M}_{4}$-mediated inhibition of 629 corticostriatal inputs (English et al., 2012; Faust et al., 2015; Pakhotin \& Bracci, 2007; 630 Witten et al., 2010). Thus, a larger dip may lead to disinhibition and higher rebound to a 631 stronger inhibition of SPNs. D2R antagonism decreases the first and enhances the 632 second which may inhibit movement initiation leading to the longer latency in lever 633 pressing. Consistent with this, we observed that the size of the cue induced dip correlates 634 with press latency (the larger the dip the shorter the latency). Surprisingly, this relationship 635 also holds true for lever presses that were performed long after the cue induced ACh 636 signal reverted to normal. This suggests that the cue-evoked dip signals the motivational 637 state of the animal. This finding is consistent with recent inhibition studies in which CIN 638 inhibition in the NAc during Pavlovian to Instrumental Transfer (PIT) enhanced the ability 639 of the pavlovian cue to invigorate behavior (Collins et al., 2019). Note, however, that mice 640 with selective Drd2 ablation do not show a deficit in PIT suggesting a more subtle deficit 641 affecting latencies rather than the level of responding (Gallo et al., 2021).

642

643 DA and ACh correlation during task-dependent behaviors 
644 Our approach to simultaneously image both DA and ACh in the same animal

645 allowed us to examine the relationship between these two neuromodulators within trials.

646 In both C57BL/6J and Drd2 ${ }^{\text {fl/fl }}$ control mice, we identified a strong negative correlation with

647 the cue-induced DA release leading the ACh dip that is attenuated by D2R antagonism.

648 This strong negative correlation between DA and ACh is significantly reduced in 649 ChATDrd2KO mice compared to Drd2fl/fl controls and ChATDrd2KO mice are unaffected

650 by D2R blockade. We also found a weaker positive correlation with DA leading ACh that 651 is enhanced by $\mathrm{D} 2 \mathrm{R}$ antagonism. We believe that this positive correlation reveals the 652 rebound in ACh activity following the dip that is blunted by D2R activation at baseline.

653 This data suggests, as discussed above, that CIN D2Rs not only modulate the ACh dip 654 but also the rebound activity.

\section{Implications for behavior}

657 What does an altered ACh signal mean for behavior? CIN selective D2R knock out mice 658 learn the Pavlovian task presented in Figure 1 as well as control littermates (data not 659 shown). This suggests that even with a shortened dip mice still can learn cue-reward 660 associations. Similarly, we recently described that enhancing the dip lengths by selective 661 overexpression of D2Rs in CINs of the NAc (D2R-OE

662 learning but was associated with a deficit in Go/No-Go learning (Gallo et al., 2021). 663 Opposite to what we found in this present study using ChATDrd2KO mice, rebound ACh 664 levels are lower in D2R-OE 665 type control mice may suppress SPN activity and responding. However, rebound activity 666 was significantly greater in incorrect No-Go (press) relative to correct No-Go (withhold) 667 trials questioning this hypothesis. Rather we observed that the ACh dip in control mice 668 was different between Go and No-Go trials, in contrast to what we observed in D2R-OE 669 mice. This difference supports the hypothesis that D2R-OE mice did not learn the switch 670 from the Go to the No-Go component of the task due to reduced contrast in ACh dip 671 information between Go and No-Go contingencies. This is consistent with prior studies 672 reporting that striatal $\mathrm{ACh}$ is not necessary for initial learning but is important for 673 behavioral performance when task contingencies change (Aoki et al., 2015; Bradfield et 
674 al., 2013; Brown et al., 2010; Favier et al., 2020; Okada et al., 2014; Okada et al., 2017; 675 Ragozzino et al., 2009).

676 In this present study, we report that D2R antagonism increases lever press latency 677 during CRF in a dose-dependent manner, but this is abolished in ChATDrd2KO mice. 678 Moreover, lever press latency correlated with the AUC of the ACH signal, which was 679 mostly driven by dip size (the larger the dip the shorter the latency) and was observed in 680 trials with latencies longer that the ACh signal lengths. As discussed, this suggests that 681 the cue-evoked dip signals the motivational state of the animal confirming a role of ACh 682 in motivated behavior (Aosaki T, 1994b; Apicella, 2007; Apicella et al., 1991; Collins et 683 al., 2019; Joshua et al., 2008; Kimura et al., 1984; Morris et al., 2004; Nougaret \& Ravel, 684 2015; Ravel et al., 2003; Shimo \& Hikosaka, 2001).

685 In conclusion, our data demonstrate that the stimulus induced ACh dip is 686 multiphasic, encompassing a DA component and a non-DA component. Striatal DA is 687 responsible for confining the temporal boundaries of the ACh dip and preventing rebound 688 excitation via CIN D2R. Notably, we also find a positive correlation between the size of 689 the stimulus induced ACh dip and behavioral responding, which implicates a role for ACh 690 in motivated behaviors. Thus, further dissection of this system will provide a better 691 understanding of the different components of the ACh dip and what each component 692 represents for specific striatal functions and behavior. 


\section{Supplemental figures:}

706

707 Figure S1:

A

DA

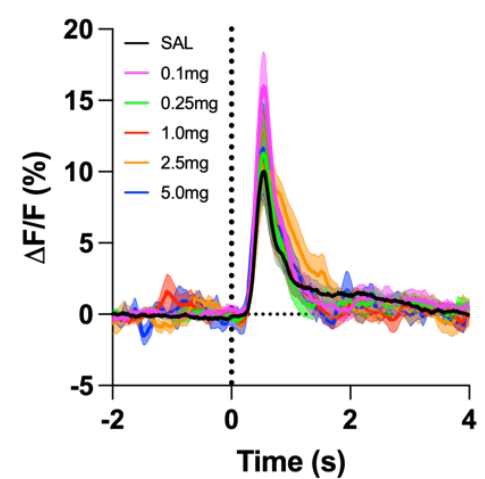

B

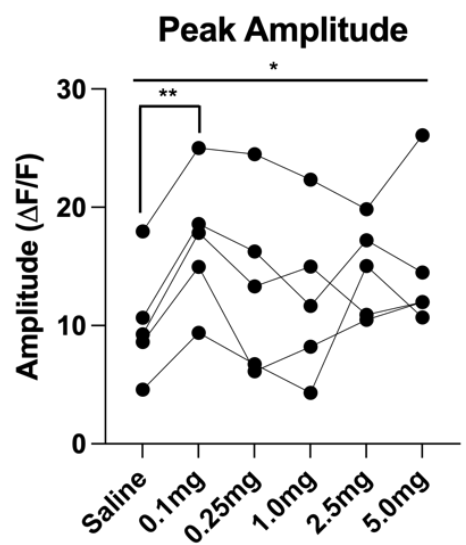

C

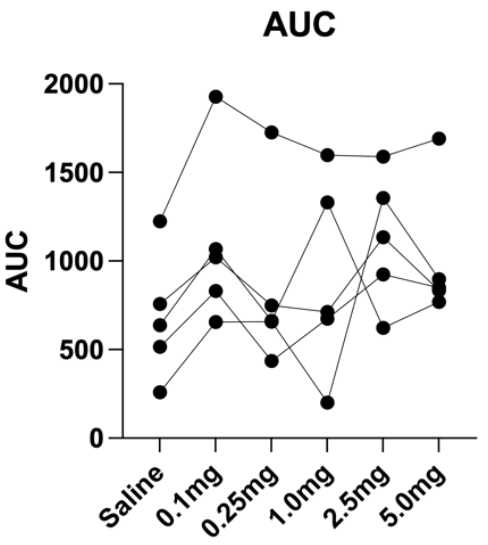

Supplementary Figure 1. D2R antagonism increases phasic DA release. (A) Changes in DA fluorescence $(\Delta F / F$ $(\%)$ ) aligned to lever extension with saline (black) and increasing doses of eticlopride: $0.1 \mathrm{mg} / \mathrm{kg}$ (pink), $0.25 \mathrm{mg} / \mathrm{kg}$ (green), $1.0 \mathrm{mg} / \mathrm{kg}$ (red), $2.5 \mathrm{mg} / \mathrm{kg}$ (orange) and $5.0 \mathrm{mg} / \mathrm{kg}$ (blue) in C57BL/6J mice. (B) Peak amplitude is increased by eticlopride in a dose-dependent manner $\left(\mathrm{F}_{(2.201,8.805)}=4.268, p=0.0480\right)$. The most prominent increase in peak

714 Figure S2:

A

DA

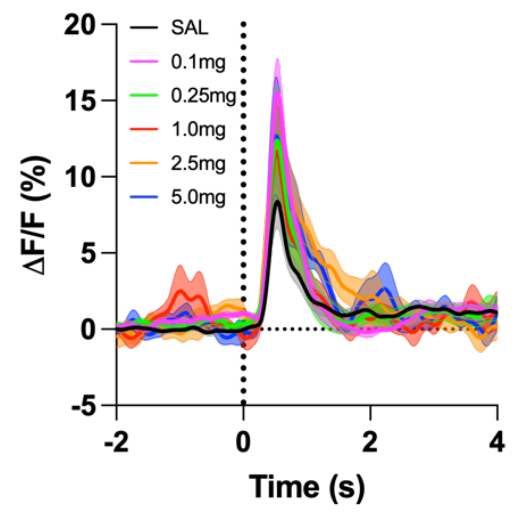

B

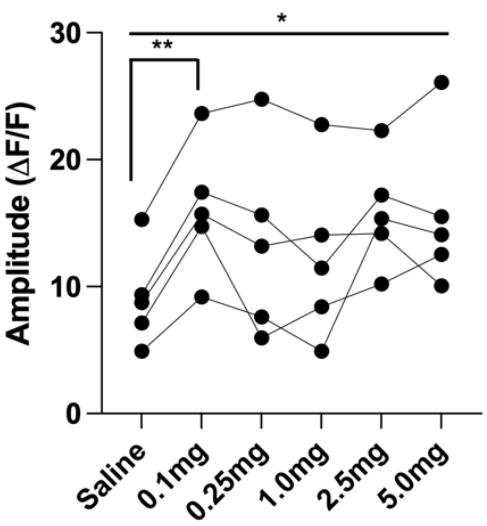

C

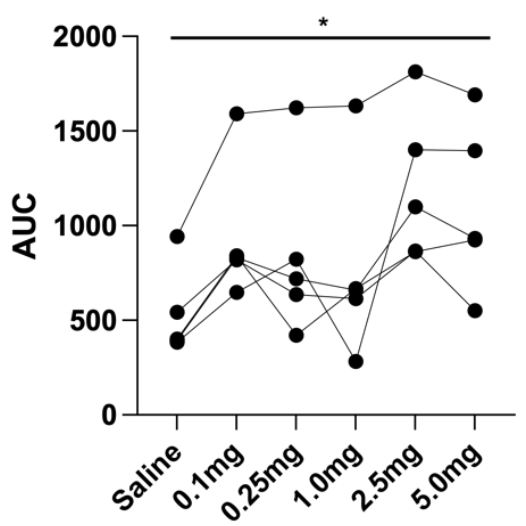

Supplementary Figure 2. D2R antagonism enhances cue evoked DA release for trials with press latencies > 2s. (A) Changes in DA fluorescence $(\Delta \mathrm{F} / \mathrm{F}(\%))$ aligned to lever extension for only trials with press latencies $>2 \mathrm{~s}$ with increasing doses of eticlopride in C57BL/6J mice. (B) Peak amplitude of DA is increased by eticlopride in a dosedependent manner $\left(F_{(2.785,11.14)}=5.804, p=0.0133\right)$ with the most prominent increase between saline and $0.1 \mathrm{mg} / \mathrm{kg}$ $(p=0.0099)$. (C) DA AUC is increased by eticlopride in a dose-dependent manner $\left(F_{(1.822,7.288)}=6.872, p=0.0244\right)$. 


\section{Figure S3:}

A

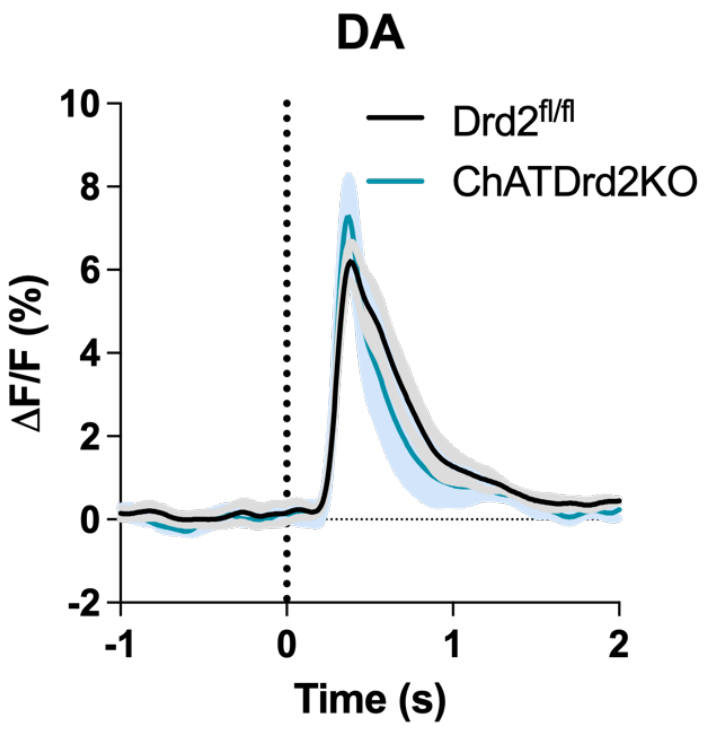

B

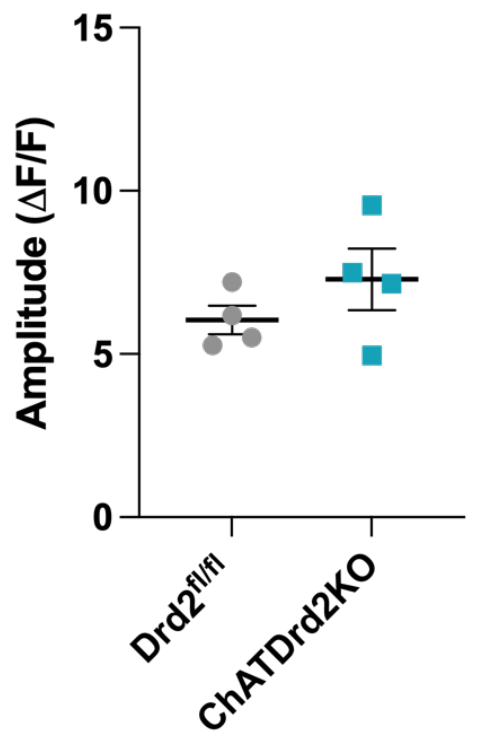

Supplementary Figure 3. Selective D2R ablation from CINs does not alter cueevoked DA release for trials with press latencies $>2 \mathrm{~s}$. (A) Changes in DA fluorescence $(\Delta F / F(\%))$ aligned to lever extension for only trials with press latencies $>2 \mathrm{~s}$ for Drd2 $2^{\mathrm{f} / \mathrm{fl}}$ control (black) and ChATDrd2KO (blue) mice, $\mathrm{N}=4 /$ genotype. (B) The DA peak amplitude is comparable between ChATDrd2KO and Drd2 ${ }^{\text {fl/fil }}$ control mice $(p=0.2744)$. 
A

\section{ACh-DA Trial Correlation}

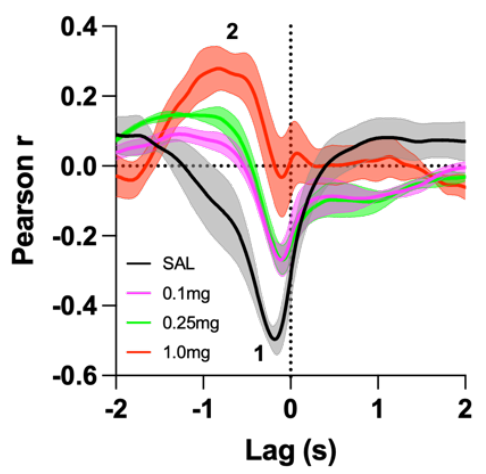

B

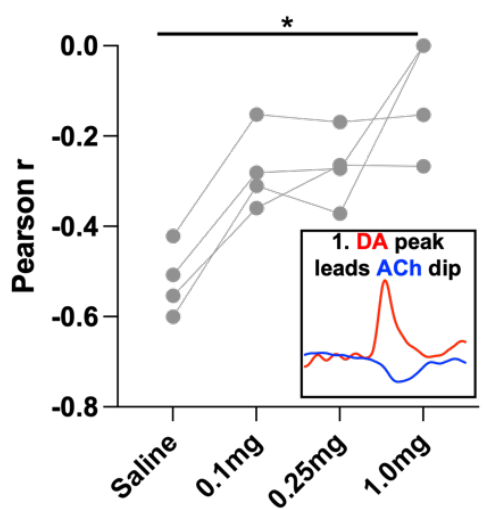

C

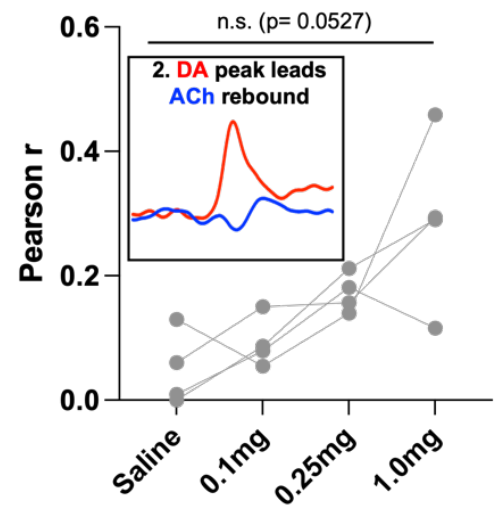

741

742

743

744

745

746

747

748

749
Supplementary Figure 4. D2R antagonism alters cue-evoked ACh-DA interactions at the lever extension. (A) Correlation between ACh and DA during CRF trials with increasing doses of eticlopride in Drd2 ${ }^{\mathrm{fl} / \mathrm{fl}}$ control mice. The ACh signal moved in front of or behind the DA signal to identify points of highest correlation. The first correlation is a negative correlation (1) with ACh lagging DA (Lag= $-167.12 \mathrm{~ms} \pm 18.82 \mathrm{~ms}$ ) and the second correlation is a positive correlation (2) with ACh lagging DA ( $\mathrm{Lag}=-1.51 \mathrm{~s} \pm 0.138 \mathrm{~s})(\mathrm{B})$ The negative correlation with the DA peak leading the ACh dip (inset) is decreased by eticlopride in a dose-dependent manner $\left(F_{(1.141,3.424)}\right.$ $=15.48, p=0.0221)$. (C) The positive correlation with the DA peak leading the ACh rebound (inset) is increased by eticlopride in a dose-dependent manner $\left(F_{(1.338,4.014)}=7.088, p=0.0527\right)$.

\section{Figure S5:}

A ACh-DA ITI Correlation

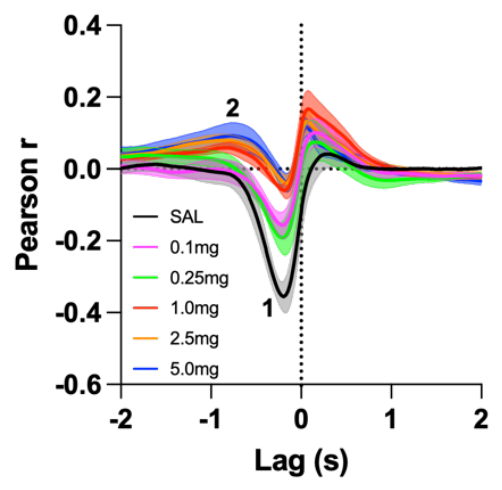

B

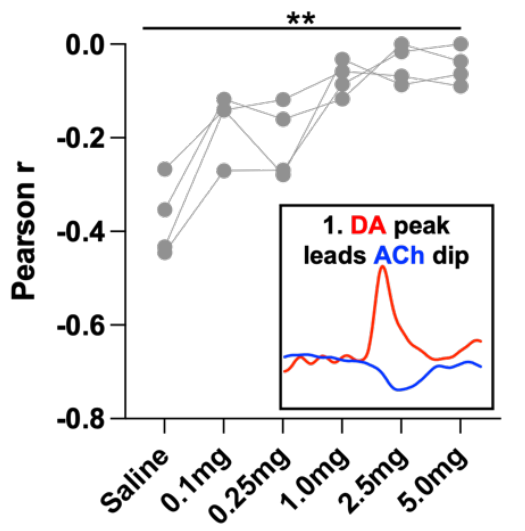

C

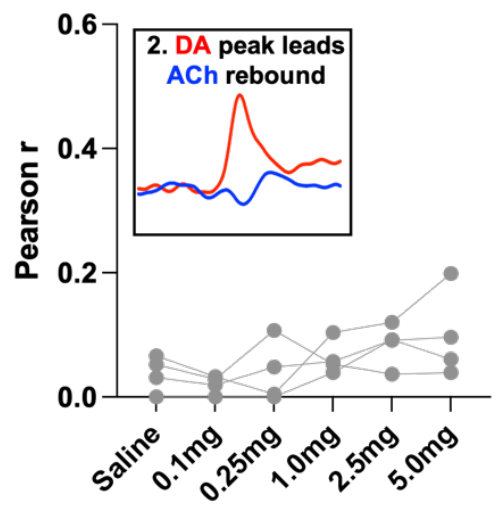

Supplementary Figure 5. D2R antagonism alters general ACh-DA interactions during the ITI in Drd2 ${ }^{\mathrm{fl} / \mathrm{fl}}$ control mice. (A) Correlation between ACh and DA during the ITI with increasing doses of eticlopride in Drd2 ${ }^{\text {f/ff }}$ control mice. The ACh signal moved in front of or behind the DA signal to identify points of highest correlation. The first correlation is a negative correlation (1) with ACh lagging DA ( $\mathrm{Lag}=-213.81 \mathrm{~ms} \pm 34.14 \mathrm{~ms}$ ) and the second correlation is a positive correlation (2) with ACh lagging DA ( $\mathrm{Lag}=-1.39 \mathrm{~s} \pm 0.208 \mathrm{~s})$ (B) The negative correlation with the DA peak leading the ACh dip (inset) is dose-dependently reduced by eticlopride $\left(F_{(2.102,6.307)}=18.68, p=\right.$ $0.0021)$. (C) The positive correlation with the DA peak leading the ACh rebound (inset) is not significantly affected by eticlopride $\left(F_{(1.276,3.827)}=2.504, p=0.1966\right)$. 
Figure S6:

A

ACh-DA Trial Correlation

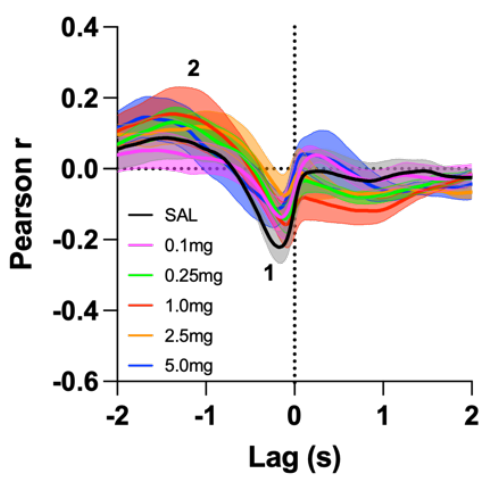

B

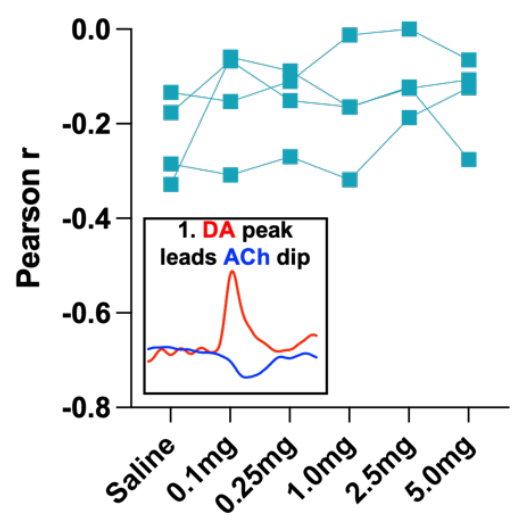

C

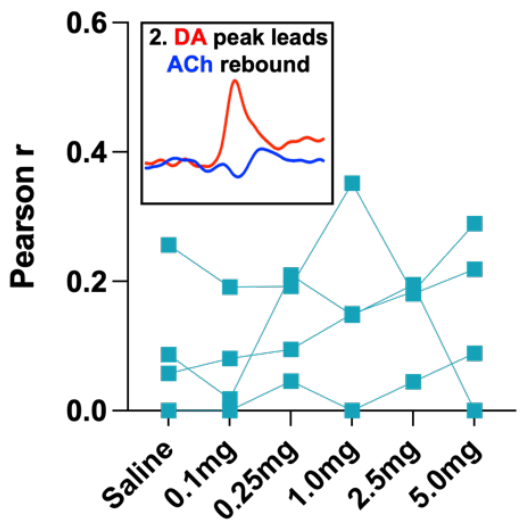

Supplementary Figure 6. D2R antagonism does not alter cue evoked ACh-DA interactions in ChATDrd2KO mice at the lever extension. (A) Correlation between ACh and DA during CRF trials with increasing doses of eticlopride in ChATDrd2KO mice. The ACh signal moved in front of or behind the DA signal to identify points of highest correlation. The first correlation is a negative correlation (1) with ACh lagging DA (Lag= $-179.41 \mathrm{~ms} \pm 30.66$ $\mathrm{ms}$ ) and the second correlation is a positive correlation (2) with ACh lagging DA (Lag= $-1.635 \mathrm{~s} \pm 0.174 \mathrm{~s}$ ). (B) The negative correlation with the DA peak leading the ACh dip (inset) is not affected by eticlopride $\left(F_{(1.720,5.161)}=1.170\right.$, $p=0.3682$ ). (C) The positive correlation with the DA peak leading the ACh rebound (inset) is not affected by eticlopride $\left(F_{(2.016,6.048)}=0.9160, p=0.4500\right)$.

772

773

774

775

776

777

778

779

780
B

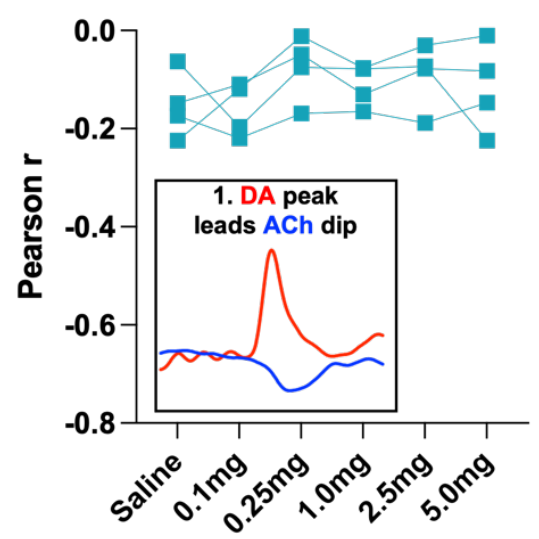

C

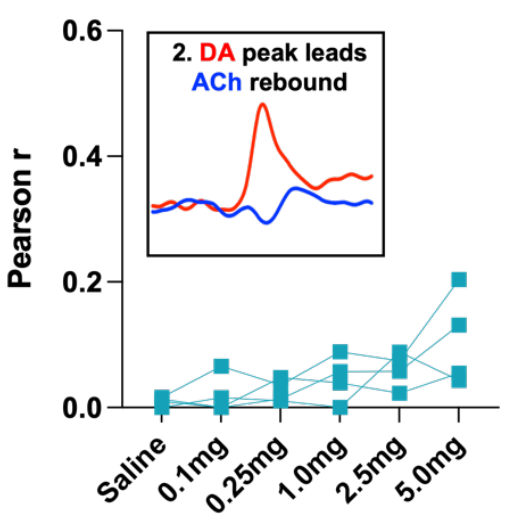

Supplementary Figure 7. D2R antagonism does not alter general ACh-DA interactions in ChATDrd2KO mice during the ITI. (A) Correlation between ACh and DA during CRF trials with increasing doses of eticlopride in ChATDrd2KO mice. The ACh signal moved in front of or behind the DA signal to identify points of highest correlation. The first correlation is a negative correlation (1) with ACh lagging DA (Lag= -282.62 ms $\pm 93.81 \mathrm{~ms}$ ) and the second correlation is a positive correlation (2) with ACh lagging DA (Lag= -1.33 $\mathrm{s} \pm 0.189 \mathrm{~s})$ (B) The negative correlation with the DA peak leading the ACh dip (inset) is not affected by eticlopride $\left(F_{(1.508,4.523)}=1.366, p=0.3275\right)$. (C) The positive correlation with the DA peak leading the ACh rebound (inset) is not affected by eticlopride $\left(F_{(1.747,5.240)}=4.839, p=\right.$ 0.0669). 
782

783

784

785

786

787

788

789

790

791

792

793

794

795

796

797

798

799

800

801

802

803

804

805

806

807

808

809

810

811

812

813

814

815

816

817

818

819

820

821

822

823

824

825

826

827

\section{References:}

Aoki, S., Liu, A. W., Zucca, A., Zucca, S., \& Wickens, J. R. (2015). Role of Striatal Cholinergic Interneurons in Set-Shifting in the Rat. J Neurosci. https://doi.org/10.1523/JNEUROSCI.0490-15.2015

Aosaki, T., Graybiel, A. M., \& Kimura, M. (1994a). Effect of the Nigrostriatal Dopamine System on Acquired Neural Responses in the Striatum of Behaving Monkeys. Science, 265(5170): 5412-5415.

Aosaki T, T. H., Ishida A, Watanabe K, Graybiel AM, Kimura M. (1994b). Responses of Tonically Active Neurons in the Primate's Striatum Undergo Systematic Changes during Behavioral Sensorimotor Conditioning. J Neurosci. https://doi.org/14(6): 3969-3984

Apicella, P. (2007). Leading tonically active neurons of the striatum from reward detection to context recognition. Trends Neurosci, 30:299-306. https://doi.org/10.1016/..tins.2007.03.011

Apicella, P., Deffains, M., Ravel, S., \& Legallet, E. (2009). Tonically active neurons in the striatum differentiate between delivery and omission of expected reward in a probabilistic task context. Eur. J. Neurosci, 30:515-526. https://doi.org/10.1111/j.1460-9568.2009.06872.x

Apicella, P., Ravel, S., Deffains, M., \& Legallet, E. (2011). The Role of Striatal Tonically Active Neurons in Reward Prediction Error Signaling during Instrumental Task Performance. J Neurosci. https://doi.org/10.1523/JNEUROSCI.4880-10.2011

Apicella, P., Scarnati, E., Ljungberg, T., \& Schultz, W. (1992). Neuronal Activity in Monkey Striatum Related to the Expectation of Predictable Environmental Events J Neurophysiol.

Apicella, P., Scarnati, E., \& Schultz, W. (1991). Tonically discharging neurons of monkey striatum respond to preparatory and rewarding stimuli. Exp Brain $\operatorname{Res}(84), 672-675$.

Augustin, S. M., Chancey, J. H., \& Lovinger, D. M. (2018). Dual Dopaminergic Regulation of Corticostriatal Plasticity by Cholinergic Interneurons and Indirect Pathway Medium Spiny Neurons. Cell Rep. https://doi.org/10.1016/j.celrep.2018.08.042.

Bello, E., Mateo, Y., Gelman, D. M., Noaín, D., Shin, J. H., Low, M. J., Alvarez, V. A., Lovinger, D. M., \& Rubinstein, M. (2011). Cocaine supersensitivity and enhanced motivation for reward in mice lacking dopamine D2 autoreceptors. Nat Neurosci, 14(18): 1033-1038. https://doi.org/10.1038/nn.2862. 
828

829

830

831

832

833

834

835

836

837

838

839

840

841

842

843

844

845

846

847

848

849

850

851

852

853

854

855

856

857

858

859

860

861

862

863

864

865

866

867

868

869

870

871

872

873

Bradfield, L. A., Bertran-Gonzalez, J., Chieng, B., \& Balleine, B. W. (2013). The thalamo-striatal pathway and cholinergic control of goal- directed action: Interlacing new and existing learning in the striatum. Neuron. https://doi.org/10.1016/j.neuron.2013.04.039.

Brown, H. D., Baker, P. M., \& Ragozzino, M. E. (2010). The Parafascicular Thalamic Nucleus Concomitantly Influences Behavioral Flexibility and Dorsomedial Striatal Acetylcholine Output in Rats. J Neurosci, 30(43):14390 -14398. https://doi.org/10.1523/JNEUROSCI.2167-10.2010

Brown, M. T. C., Tan, K. R., O'Connor, E. C., Nikonenko, I., Muller, D., \& Lüscher, C. (2012). Ventral tegmental area GABA projections pause accumbal cholinergic interneurons to enhance associative learning. Nature. https://doi.org/10.1038/nature11657

Cachope, R., \& Cheer, J. F. (2014). Local control of striatal dopamine release. Front Behav Neurosci. https://doi.org/10.3389/fnbeh.2014.00188

Cachope, R., Mateo, Y., Mathur, B. N., Irving, J., Wang, H.-L., Morales, M., Lovinger, D. M., \& Cheer, J. F. (2012). Selective activation of cholinergic interneurons enhances accumbal phasic dopamine release: setting the tone for reward processing. Cell Rep. https://doi.org/10.1016/j.celrep.2012.05.011.

Calipari, E. S., Bagot, R. C., Purushothaman, I., Davidson, T. J., Yorgason, J. T., Peña, C. J., Walker, D. M., Pirpinias, S. T., Guise, K. G., Ramakrishnan, C., Deisseroth, K., \& Neslter, E. J. (2016). In vivo imaging identifies temporal signature of D1 and D2 medium spiny neurons in cocaine reward. Proc. Natl. Acad. Sci. USA. https://doi.org/10.1073/pnas.1521238113

Chuhma, N., Mingote, S., Moore, H., \& Rayport, S. (2014). Dopamine neurons control striatal cholinergic neurons via regionally heterogeneous dopamine and glutamate signaling. Neuron. https://doi.org/10.1016/j.neuron.2013.12.027.

Collins, A. L., Aitken, T. J., Huang, I.-W., Shieh, C., Greenfield, V. Y., Monbouquette, H. G., Ostlund, S. B., \& Wassum, K. M. (2019). Nucleus accumbens cholinergic interneurons oppose cuemotivated behavior. Biol Psychiatry, 86(85): 388-396. https://doi.org/10.1016/j.biopsych.2019.02.014.

Cover, K. K., Gyawali, U., Kerkhoff, W. G., Patton, M. H., Mu, C., White, M. G., Marquardt, A. E., Roberts, B. M., Cheer, J. F., \& Mathur, B. N. (2019). Activation of the Rostral Intralaminar Thalamus Drives Reinforcement through Striatal Dopamine Release. Cell Rep. https://doi.org/10.1016/j.celrep.2019.01.044

Cragg, S. J. (2006). Meaningful silences: how dopamine listens to the ACh pause. Trends Neurosci. https://doi.org/10.1016/j.tins.2006.01.003 
874

875

876

877

878

879

880

881

882

883

884

885

886

887

888

889

890

891

892

893

894

895

896

897

898

899

900

901

902

903

904

905

906

907

908

909

910

911

912

913

914

915

916

917

918

919

Day, J. J., Roitman, M. F., Wightman, R. M., \& Carelli, R. M. (2007). Associative learning mediates dynamic shifts in dopamine signaling in the nucleus accumbens. Nat Neurosci, 1020-1028. https://doi.org/10.1038/nn1923

Ding, J. B., Guzman, J. N., Peterson, J. D., Goldberg, J. A., \& Surmeier, D. J. (2010). Thalamic gating of corticostriatal signaling by cholinergic interneurons. Neuron. https://doi.org/10.1016/j.neuron.2010.06.017.

Doig, N. M., Magill, P. J., Apicella, P., Bolam, J. P., \& Sharott, A. (2014). Cortical and Thalamic Excitation Mediate the Multiphasic Responses of Striatal Cholinergic Interneurons to Motivationally Salient Stimuli. J Neurosci. https://doi.org/10.1523/JNEUROSCI.4627-13.2014

English, D. F., Ibanez-Sandoval, O., Stark, E., Tecuapetla, F., Buzsáki, G., Deisseroth, K., Tepper, J. M., \& Koos, T. (2012). GABAergic circuits mediate the reinforcement-related signals of striatal cholinergic interneurons. Nat Neurosci. https://doi.org/10.1038/nn.2984

Faust, T. W., Assous, M., Shah, F., Tepper, J. M., \& Koós, T. (2015). Novel Fast Adapting Interneurons Mediate Cholinergic-Induced Fast GABAA IPSCs In Striatal Spiny Neurons. Eur. J. Neurosci(42(2)), 1764-1774. https://doi.org/10.1111/ejn.12915.

Favier, M., Janickova, H., Justo, D., Kljakic, O., Runtz, L., Natsheh, J. Y., Pascoal, T. A., Germann, J., Gallino, D., Kang, J.-I., Meng, X. Q., Antinora, C., Raulic, S., Jacobsen, J. P. R., Moquin, L., Vigneuault, E., Gratton, A., Caron, M. G., Duriez, P., Brandon, M. P., Neto, P. R., Chakravarty, M. M., Herzallah, M. M., Gorwood, P., Prado, M. A., Prado, V. F., \& Mestikawy, S. E. (2020). Cholinergic dysfunction in the dorsal striatum promotes habit formation and maladaptive eating. Journal of Clinical Investigation, 130(112):6616-6630. https://doi.org/10.1172/JCl138532.

Gallo, E. F., Greenwald, J., Yeisley, J., Teboul, E., Martyniuk, K. M., Vallarin, J. M., Li, Y., Javith, J. A., Balsam, P. D., \& Kellendonk, C. (2021). Dopamine D2 receptors modulate the cholinergic pause and inhibitory learning Mol Psychiatry. https://doi.org/10.1038/s41380-021-01364-y

Helseth AR, H.-M. R., Hall VL, Oliver ML, Turner BD, Caffall ZF, Rittiner JE, Shipman MK, King CS, Gradinaru V, Gerfen C, Costa-Mattioli M, Calakos N. (2021). Cholinergic neurons constitutively engage the ISR for dopamine modulation and skill learning in mice. Science, 372(6540), eabe1931. https://doi.org/doi:10.1126/science.abe1931

Jing, M., Li, Y., Zeng, J., Huang, P., Skirzewski, M., Kljakic, O., Peng, W., Qian, T., Tan, K., Zou, J., Trinh, S., Wu, R., Zhang, S., Pan, S., Hires, S. A., Xu, M., Li, H., Saksida, L. M., Prado, V. F., Bussey, T. J., Prado, M. A. M., Chen, L., Cheng, H., \& Li, Y. (2020). An optimized acetylcholine sensor for monitoring in vivo 
cholinergic activity. Nat Methods, 17, 1139-1146. https://doi.org/10.1038/s41592$\underline{020-0953-2}$

Joshua, M., Adler, A., Mitelman, R., Vaadia, E., \& Bergman, H. (2008). Midbrain Dopaminergic Neurons and Striatal Cholinergic Interneurons Encode the Difference between Reward and Aversive Events at Different Epochs of Probabilistic Classical Conditioning Trials. J Neurosci. https://doi.org/10.1523/JNEUROSCl.3839-08.2008

Kharkwal, G., Brami-Cherrier, K., Lizardi-Ortiz, J. E., Nelson, A. B., Ramos, M., Barrio, D. D., Sulzer, D., Kreitzer, A. C., \& Borrelli, E. (2016). Parkinsonism driven by antipsychotics originates from dopaminergic control of striatal cholinergic interneurons. Neuron. https://doi.org/10.1016/j.neuron.2016.06.014.

Kimura, M., Rajkowski, J., \& Evarts, E. (1984). Tonically discharging putamen neurons exhibit set-dependent responses. Proc. Natl. Acad. Sci. USA.

Labouesse, M. A., \& Patriarchi, T. (2021). A versatile GPCR toolkit to track in vivo neuromodulation: not a one-size-fits-all sensor. Neuropsychopharmacol, 46, 2043-2047. https://doi.org/10.1038/s41386-021-00982-y

Matamales, M., Skrbis, Z., Hatch, R. J., Balleine, B. W., Götz, J., \& Bertran-Gonzalez, J. (2016). Aging-Related Dysfunction of Striatal Cholinergic Interneurons Produces Conflict in Action Selection. Neuron. https://doi.org/10.1016/j.neuron.2016.03.006

Matsumoto, N., Minamimoto, T., Graybiel, A. M., \& Kimura, M. (2000). Neurons in the Thalamic CM-Pf Complex Supply Striatal Neurons With Information About Behaviorally Significant Sensory Events. J Neurophysiol. https://doi.org/10.1152/jn.2001.85.2.960

Maurice, N., Liberge, M., Jaouen, F., Ztaou, S., Hanini, M., Camon, J., Deisseroth, K., Amalric, M., Goff, L. K.-L., \& Beurrier, C. (2015). Striatal Cholinergic Interneurons Control Motor Behavior and Basal Ganglia Function in Experimental Parkinsonism. Cell Rep. https://doi.org/10.1016/j.celrep.2015.09.034

Mohebi, A., Pettibone, J. R., Hamid, A. A., Wong, J.-M. T., Vinson, L. T., Patriarchi, T., Tian, L., Kennedy, R. T., \& Berke, J. D. (2019). Dissociable dopamine dynamics for learning and motivation. Nature, 65-70. https://doi.org/10.1038/s41586-019$\underline{1235-y}$

Morris, G., Arkadir, D., Nevet, A., Vaadia, E., \& Bergman, H. (2004). Coincident but Distinct Messages of Midbrain Dopamine and Striatal Tonically Active Neurons. Neuron. https://doi.org/2004;43:133-143. 
964

965

966

967

968

969

970

971

972

973

974

975

976

977

978

979

980

981

982

983

984

985

986

987

988

989

990

991

992

993

994

995

996

997

998

999

1000

1001

1002

1003

1004

1005

1006

1007

1008

1009
Nasser, H., Calu, D. J., Schoenbaum, G., \& Sharpe, M. J. (2017). The Dopamine Prediction Error: Contributions to Associative Models of Reward Learning. Front Psychol. https://doi.org/10.3389/fpsyg.2017.00244

Nougaret, S., \& Ravel, S. (2015). Modulation of Tonically Active Neurons of the Monkey Striatum by Events Carrying Different Force and Reward Information. J Neurosci. https://doi.org/10.1523/JNEUROSCl.0039-15.2015

Okada, K., Nishizawa, K., Fukabori, R., Kai, N., Shiota, A., Ueda, M., Tsutsui, Y., Sakata, S., Matsushita, N., \& Kobayashi, K. (2014). Enhanced flexibility of place discrimination learning by targeting striatal cholinergic interneurons. https://doi.org/10.1038/ncomms4778

Okada, K., Nishizawa, K., Setogawa, S., Hashimoto, K., \& Kobayashi, K. (2017). Taskdependent function of striatal cholinergic interneurons in behavioural flexibility. Eur. J. Neurosci. https://doi.org/10.1111/ejn.13768.

Pakhotin, P., \& Bracci, E. (2007). Cholinergic Interneurons Control the Excitatory Input to the Striatum. $J$ Neurosci(27(2)), 391-400.

Patriarchi, T., Cho, J. R., Merten, K., Howe, M. W., Marley, A., Xiong, W.-H., Folk, R. W., Broussard, G. J., Liang, R., Jang, M. J., Zhong, H., Dombeck, D., Zastrow, M. v., Nimmerjahn, A., Gradinaru, V., Williams, J. T., \& Tian, L. (2018). Ultrafast neuronal imaging of dopamine dynamics with designed genetically encoded sensors. Science. https://doi.org/10.1126/science.aat4422

Pisansky, M. T., Lefevre, E. M., Retzlaff, C. L., Trieu, B. H., Leipold, D. W., \& Rothwell, P. E. (2019). Nucleus Accumbens Fast-Spiking Interneurons Constrain Impulsive Action. Biol Psychiatry, 86(11), 836-847. https://doi.org/10.1016/j.biopsych.2019.07.002

Ragozzino, M. E., Mohler, E. G., Prior, M., Palencia, C. A., \& Rozman, S. (2009). Acetylcholine Activity in Selective Striatal Regions Supports Behavioral Flexibility. Neurobiol Learn Mem, 91(91): 13-22. https://doi.org/10.1016/j.nlm.2008.09.008.

Ravel, S., Legallet, E., \& Apicella, P. (2003). Responses of Tonically Active Neurons in the Monkey Striatum Discriminate between Motivationally Opposing Stimuli. $J$ Neurosci(23), 8489-8497.

Rossi, J., Balthasar, N., Olson, D., Scott, M., Berglund, E., Lee, C. E., Choi, M. J., Lauzon, D., Lowell, B. B., \& Elmquist, J. K. (2011). Melanocortin-4 Receptors Expressed by Cholinergic Neurons Regulate Energy Balance and Glucose Homeostasis. Cell Metab, 13, 195-204. https://doi.org/10.1016/j.cmet.2011.01.010 
1010

1011

1012

1013

1014

1015

1016

1017

1018

1019

1020

1021

1022

1023

1024

1025

1026

1027

1028

1029

1030

1031

1032

1033

1034

1035

1036

1037

1038

1039

1040

1041

1042

1043

1044

1045

1046

1047

1048

1049

1050

1051

1052

1053

1054

1055

Schultz, W. (2007). Behavioral dopamine signals. Trends Neurosci. https://doi.org/10.1016/j.tins.2007.03.007

Schultz, W., Dayan, P., \& Montague, P. R. (1997). A Neural Substrate of Prediction and Reward. Science. https://doi.org/10.1126/science.275.5306.1593.

Shimo, Y., \& Hikosaka, O. (2001). Role of Tonically Active Neurons in Primate Caudate in Reward-Oriented Saccadic Eye Movement. J Neurosci(19), 7804-7814.

Steinberg, E. E., Keiflin, R., Boivin, J. R., Witten, I. B., Deisseroth, K., \& Janak, P. H. (2013). A causal link between prediction errors, dopamine neurons and learning. Nat Neurosci, 966-973 https://doi.org/10.1038/nn.3413

Straub, C., Tritsch, N. X., Hagan, N. A., Gu, C., \& Sabatini, B. L. (2014). Multiphasic Modulation of Cholinergic Interneurons by Nigrostriatal Afferents. J Neurosci. https://doi.org/10.1523/JNEUROSCI.0589-14.2014

Sulzer, D., Cragg, S. J., \& Rice, M. E. (2016). Striatal dopamine neurotransmission: Regulation of release and uptake. Basal Ganglia. https://doi.org/10.1016/j.baga.2016.02.001

Threlfell, S., Lalic, T., Platt, N. J., Jennings, K. A., Deisseroth, K., \& Cragg, S. J. (2012). Striatal Dopamine Release Is Triggered by Synchronized Activity in Cholinergic Interneurons. Neuron. https://doi.org/10.1016/j.neuron.2012.04.038

Watanabe, K., \& Kimura, M. (1998). Dopamine Receptor-Mediated Mechanisms Involved in the Expression of Learned Activity of Primate Striatal Neurons. $J$ Neurophysiol. https://doi.org/10.1152/jn.1998.79.5.2568

Wieland, S., Du, D., Oswald, M. J., Parlato, R., Köhr, G., \& Kelsch, W. (2014). Phasic Dopaminergic Activity Exerts Fast Control of Cholinergic Interneuron Firing via Sequential NMDA, D2, and D1 Receptor Activation. J Neurosci. https://doi.org/10.1523/JNEUROSCl.1175-14.2014

Wilson, C. J. (2005). The Mechanism of Intrinsic Amplification of Hyperpolarizations and Spontaneous Bursting in Striatal Cholinergic Interneurons. Neuron. https://doi.org/10.1016/j.neuron.2004.12.053

Witten, I. B., Lin, S.-C., Brodsky, M., Prakash, R., Diester, I., Anikeeva, P., Gradinaru, V., Ramakrishnan, C., \& Deisseroth, K. (2010). Cholinergic Interneurons Control Local Circuit Activity and Cocaine Conditioning. Science. https://doi.org/10.1126/science.1193771.

Yan, Z., \& Surmeier, D. J. (1991). D5 Dopamine Receptors Enhance Zn21-Sensitive GABAA Currents in Striatal Cholinergic Interneurons through a PKA/PP1 Cascade. Neuron. https://doi.org/10.1016/s0896-6273(00)80402-x. 
Zhang, Y.-F., \& Cragg, S. J. (2017). Pauses in Striatal Cholinergic Interneurons: What is 1058 1059 Revealed by Their Common Themes and Variations? Front Syst Neurosci.

1063 https://doi.org/10.3389/fnsys.2017.00080

1064

1065

Zhang, Y.-F., Reynolds, J. N. J., \& Cragg, S. J. (2018). Pauses in Cholinergic Interneuron Activity Are Driven by Excitatory Input and Delayed Rectification with Dopamine Modulation. Neuron. https://doi.org/10.1016/j.neuron.2018.04.027 